\title{
Time inconsistency and endogenous borrowing constraints
}

\section{CAMA Working Paper 57/2020 June 2020}

Joydeep Bhattacharya

lowa State University

\section{Monisankar Bishnu}

ISI, Delhi

Centre for Applied Macroeconomic Analysis, ANU

\author{
Min Wang \\ NSD, Peking University
}

\section{Abstract}

This paper studies the welfare of time-inconsistent, partially sophisticated agents living under two different regimes, one with complete, unfettered credit markets (CM) and the other with endogenous borrowing constraints (EBC) where the borrowing limits are set to make agents indifferent between defaulting and paying back their unsecured loans. The $\mathrm{CM}$ regime cannot deliver the first best because partially sophisticated agents would undo plans laid out by previous selves and borrow too much. Somewhat counterintuitively, in some cases, the EBC regime may deliver higher welfare than the $\mathrm{CM}$ regime. These results speak to the academic debate surrounding the creation and functioning of the CFPB (Consumer Financial Protection Bureau) in the U.S. and its implementation of the ability-to-repay rule on lenders after the 2007-8 crisis. Such institutions generate commitment publicly and may help time inconsistent agents economize on the costs of private commitment provision. 


\title{
Keywords
}

endogenous borrowing constraints, overborrowing, financial protection

\author{
JEL Classification
}

E21, E70, G40, G28

\section{Address for correspondence:}

(E) cama.admin@anu.edu.au

ISSN 2206-0332

The Centre for Applied Macroeconomic Analysis in the Crawford School of Public Policy has been established to build strong links between professional macroeconomists. It provides a forum for quality macroeconomic research and discussion of policy issues between academia, government and the private sector.

The Crawford School of Public Policy is the Australian National University's public policy school, serving and influencing Australia, Asia and the Pacific through advanced policy research, graduate and executive education, and policy impact. 


\title{
TIME INCONSISTENCY AND ENDOGENOUS BORROWING CONSTRAINTS
}

\author{
JOYDEEP BHATTACHARYA* \\ Iowa State University
}

\author{
MONISANKAR BISHNU ${ }^{\dagger}$ \\ ISI, Delhi \& CAMA
}

\author{
MIN WANG ${ }^{\ddagger}$ \\ NSD, Peking University
}

June 10, 2020

\begin{abstract}
This paper studies the welfare of time-inconsistent, partially sophisticated agents living under two different regimes, one with complete, unfettered credit markets (CM) and the other with endogenous borrowing constraints (EBC) where the borrowing limits are set to make agents indifferent between defaulting and paying back their unsecured loans. The CM regime cannot deliver the first best because partially sophisticated agents would undo plans laid out by previous selves and borrow too much. Somewhat counterintuitively, in some cases, the EBC regime may deliver higher welfare than the CM regime. These results speak to the academic debate surrounding the creation and functioning of the CFPB (Consumer Financial Protection Bureau) in the U.S. and its implementation of the ability-to-repay rule on lenders after the 2007-8 crisis. Such institutions generate commitment publicly and may help timeinconsistent agents economize on the costs of private commitment provision.
\end{abstract}

JEL: E 21, E 70, G 40, G 28

Keywords: endogenous borrowing constraints, overborrowing, financial protection

\footnotetext{
${ }^{*}$ Department of Economics, Iowa State University, Ames IA 50011-1070, USA. E-mail: joydeep@iastate.edu

${ }^{\dagger}$ Economics and Planning Unit, Indian Statistical Institute, India; Centre for Applied Macroeconomic Analysis, Australian National University, Australia. E-mail: mbishnu@isid.ac .in

${ }^{\ddagger}$ Corresponding author. National School of Development, Peking University, Beijing 100871, China; E-mail: wangmin@nsd.pku.edu.cn
} 


\section{Introduction}

On the face of it, access to unfettered credit seems like a good thing. It offers households muchneeded flexibility in managing their consumption over time, allowing them to better smooth income or consumption shocks. ${ }^{1}$ However, when households make "mistakes" - underestimate their future interest payments or fail to commit themselves to a plan of steady repayment - the future costs of borrowing can outweigh the initial benefits and hurt them, even from an exante perspective. Models of time-inconsistent, hyperbolic preferences (Laibson,1997) have been used to explain this sort of faulty consumer borrowing. ${ }^{2}$ Individuals with these preferences will at times choose to borrow (or borrow "too much") even when they know, or have a sense, they shouldn't. They borrow under the "flawed" assumption that they will repay the loan at some date, but cannot commit to this plan. ${ }^{3}$ To some, this suggests a role for policy intervention, perhaps a policy that constrains such individuals' consumption in the current period by, say, removing or curtailing a source of credit. This paper investigates and formalizes the above discussed tension, between an unfettered and a controlled credit regime, in a lifecycle model with time-inconsistent agents. It uses the structure to ask, when is policy intervention desirable? And if so, when is it most effective?

These questions are not merely of theoretical interest. They lie at the heart of the academic debate surrounding the creation and functioning of the CFPB (Consumer Financial Protection Bureau) in the U.S. in the years after the 2007-8 financial crisis, a crisis that caused panic and long-lasting financial turmoil around the world. A major contributory factor for this crisis was "too much borrowing": borrowers were able to borrow more than ever before as lenders approved "no documentation" loans which did not require verification of a borrower's income and assets. ${ }^{4}$ A lot changed with the 2010 Dodd-Frank Act and the subsequent creation of the CFPB, specifically its ability-to-repay rule which mandated lenders to verify that their loan recipients have the financial means to pay back. Also added was the mandatory "know before you owe" disclosures that inform borrowers how much they need to budget for their loan payments before they sign on the dotted line. While the CFPB is generally considered a success (there is vast

\footnotetext{
${ }^{1}$ Historically, in the first half of post war U.S., institutional actors were mainly in charge of managing the financial affairs of American households. Subsequently, as Ryan et al. (2011) point out, a "do-it-yourself" style of consumer finance [emerged], by which consumers were not only allowed to make financial choices, but were also frequently forced to make financial choices."

${ }^{2}$ There is a fair bit of evidence linking hyperbolic preferences to overborrowing. Gathergood (2012) finds among U.K. consumers, "over-indebtedness, measured both as delinquency on repayments and self-reported financial distress, occurs disproportionately among individuals who report self-control problems.” See also Xiao and Porto (2019) for similar findings from Chinese data.

${ }^{3}$ Ryan et al. (2011) point to the fact that in the U.S. in the 1960s, installment credit with fixed repayment terms was steadily replaced by revolving credit which permitted borrowers to customize the repayment (including the emergence of low minimum payments). "By the 1980s, required minimum monthly payments were dramatically reduced, such that a consumer could literally finance a dinner at a restaurant over a period of years." This is precisely how present bias entered the picture.

${ }^{4}$ We are not suggesting that behavioral mistakes are the only factor explaining the dramatic increase in indebtedness of Americans. Some of the blame, of course, goes to regulation: "an explicit national goal of greater homeownership generated bipartisan support for mortgage subsidies" and the many tax susidies that followed.
} 
support for it from the general public), there is also little doubt that the regulations it introduced made it harder for many people, including "sound borrowers", to get loans.

This paper offers a stylized recreation of this debate. It studies a lifecycle model that captures the essence of the natural life-cycle pattern of borrowing and saving: borrowing as young, saving as middle-aged, and dissaving as old. We employ ideas about present-biasedness and associated self-awareness popular in the literature. From Laibson (1997), we adopt the notion that individuals are comprised of multiple selves, possibly in conflict with one another: there may be disagreements - preference reversal - between the preferences of the current young self and her future selves. Time-inconsistent preferences (quasi-hyperbolic discounting) help explain the gap between what the current, decision-making self wishes a future self to save and what that self, when her turn to decide arrives, actually does. Much depends on the self-awareness of the current self. Following O'Donoghue and Rabin (2001), we allow for partial naivete (sophistication) where the current self has beliefs about the time preference of future selves that are, in principle, different from the actual preference of the latter. This means the agent is aware she will have to wrestle with self-control problems in the future but is not fully aware of their magnitude. The more aware the young self is of the impending preference reversal, the more sophisticated she is, and the stronger her desire to protect the consumption possibilities of her future selves.

In such a setting, we start by studying activities in a complete ("unfettered") credit market, $\mathrm{CM}$ henceforth. Here, an agent can borrow "any" amount she wishes at the going market interest rate and every loan is repaid on time. The fully naive young mistakenly believes she has full buyin from her future selves and decides on what she thinks is the optimal path of saving. The sophisticated young, on the other hand, realizes her middle-aged self would deviate from this path and consume too much (save too little for old age). To "correct" this, she could raise her own saving, raising middle-aged wealth, allowing the middle-aged to partly indulge her present bias. The problem is, a lot of this increased wealth could end up consumed by the middle-aged and only a small portion passed on as higher wealth to the old. From the perspective of the sophisticated young, the latter effect is desirable but not the former. In short, the simultaneous reduction of middle-age consumption and increase of old-age consumption, while desirable for the young self, is not possible under the one tool she has at her disposal, her youthful asset holding. The upshot is that while the young agent most prefers her preferred solution - the first best - she cannot achieve it sans further intervention because of the innate time inconsistency. And this is true even if the agent is fully sophisticated.

In a stylized fashion, this represents the world before the advent of the CFPB. The market lends too much, borrowers borrow too much, and the first best is unattainable. We go on to study a world that roughly corresponds to life after the CFPB's regulations - especially the ability-torepay rule - are in place. Specifically, we explore a setting à la Kehoe and Levine (1993), Zhang (1997) and Azariadis and Lambertini (2003) in which loan repayment is strategic and, therefore, not assured. Hence, creditors allow an individual to borrow up to a limit ("endogenous borrow- 
ing constraint", hereafter EBC) that is in her interest to repay, or parenthetically, what the lender deems is the borrower's ability to repay. ${ }^{5}$

Clearly, in this setup, not everyone will be allowed to borrow; even those who are will not be granted as big a loan as they would have received in the CM world. But recall, the problem in the CM world was that, even a fully sophisticated agent, armed solely with own saving as the only tool under her belt, could do little to curb the excesses of her future selves. Here, under the $\mathrm{EBC}$ regime, she gets some assistance from the market. Strikingly, we find that if agents are sufficiently risk averse, the welfare of some naive and some partially sophisticated agents under the EBC regime may be higher than in the CM world. In a stylized way, this offers theoretical endorsement of the CFPB. Yes, some "sound borrowers" do not get credit, and some borrowers do not get as much credit as they would have under the lax pre-CFPB world, but for many, the ability-to-repay rule on lenders (hence, an EBC on borrowers) in the post-CFPB world offers much needed help with their own fight with time-inconsistency.

Beyond the ability-to-repay mandate, what can (and should) governments do? Given the young are natural borrowers and the middle-aged, savers, it is conceivable a policy that taxes the latter and transfers to the former (and the old) could help curb the overborrowing of the middle-aged and prevent underconsumption by the old. Such a policy would be consistent with the thinking in Boldrin and Montes (2005), Bishnu (2013), Wang (2014) and Bishnu et al. (2020) where time consistent agents in an imperfect credit market world benefit from a joint institutional arrangement (connecting education expenses when young and pension payouts when old). Such an arrangement acts as a stand-in for the missing (education) loan market and can replicate the complete market allocations. By way of contrast, in our setup with time inconsistent agents and perfect credit markets, this insight no longer holds: private agents fully offset any such tax-transfer intervention by changing their own asset holdings and, hence, are powerless - see Andersen and Bhattacharya (2019) - at preventing the middle-aged from revising plans set by the young. We go on to show that, all else same, if these agents were instead in the EBC world, the borrowing constraints therein would successfully restrict overborrowing by the middle-aged de facto forcing the agents to follow the first best path in their entire life. ${ }^{6}$

While the literature on present-bias and partial naivete in the context of saving and credit markets is vast (see Tanaka and Murooka (2012) and Beshears et al. (2018)), to the best of our knowledge, there isn't much written on the beneficial role played by credit market frictions in helping consumers with their self control problems. ${ }^{7}$ For sure, we know how demand for com-

\footnotetext{
${ }^{5}$ There is, by now, a substantial literature on behavioral contract theory (Koszegi, 2014) that studies the ability of firms (lenders) to exploit the naivete of consumers by offering certain contracts that encourage overborrowing. We do not take up this issue here.

${ }^{6}$ Krueger and Perri (2001) are interested in studying if tax policy designed to reduce income (and hence, consumption) risk may worsen the same when private insurance contracts are unenforceable in the spirit of Kehoe and Levine (1993). The idea is the following. If agents default on their private debt, they are excluded from consumption smoothing via the market. In their setup, as in Andolfatto and Gervais (2006), taxes and transfers can lessen the blow from being excluded and worsen the enforeceability of private contracts. For an updated look at this issue, see Broer et al. (2017).

${ }^{7}$ Heidhues and Kőszegi (2010) study a setting in which partially sophisticated consumers overborrow, pay the
} 
mitment assets arise in environments where agents face self control problems. Here, such private commitment assets and technologies are absent: we show how the market in the EBC world, with the help of an outside agency such as the CFPB, can act as a stand-in for their absence. There is a deeper point here. If such private commitment assets were present and being traded at a positive price, some agents would use valuable resources to invest in them thereby shrinking their consumption possibilities. The market, via agencies like the CPFB, economizes on such expenses by generating the commitment publicly.

The rest of the paper is organized as follows. Section 2 lays out the primitives of the model economy and defines notions of present bias and sophistication. Section 3 studies optimal allocations in the complete credit markets setting while Section 4 studies the same in the economy with endogenous borrowing constraints. Section 5 compares welfare in the two settings and Section 6 explores the role of government policy. Section 7 contains some concluding remarks. The appendix contains some proofs and accompanying discussion.

\section{The model}

\subsection{Primitives}

We consider a simple, three-period lifecycle model so as to capture the essence of the natural life-cycle pattern: borrowing as young $(y)$, saving as middle-aged $(m)$ and dissaving as old $(o)$. At times below, we refer to these phases of the lifecycle as selves. There is no within-cohort heterogeneity of any kind. The population size stays fixed. This is a small, open economy with a fixed interest rate, $R>1$; loanable funds are available at this rate. A representative agent is born with an endowment profile $\left(\omega_{y}, \omega_{m}, \omega_{o}\right) \in \Re_{+}^{3}$. There is also a governmental authority whose actions, described further below, will conform roughly to that of the CFPB.

Any agent born in period $t$ draws utility from $\left(c_{y}, c_{m}, c_{o}\right)$, denoting consumption in youth, middle age and old age, respectively. Following Laibson (1997), the preferences when young are given as

$$
U\left(c_{y}, c_{m}, c_{o}\right)=u\left(c_{y}\right)+\beta \delta\left[u\left(c_{m}\right)+\delta u\left(c_{o}\right)\right]
$$

when middle aged as

$$
\text { (2) } U\left(c_{m}, c_{o}\right)=u\left(c_{m}\right)+\beta \delta u\left(c_{o}\right) \text {, }
$$

requisite penalties, and back load repayment, thereby suffering a welfare loss. They find that not allowing lenders to impose large penalties for deferring small amounts of repayment, in line with current practice in the U.S. credit-card and mortgage markets, can improve welfare. In their setup, unlike in ours, a defaulter may re-enter the contract by paying a penalty. 
and when old as

(3) $U\left(c_{o}\right)=u\left(c_{o}\right)$

where $\delta \in[0,1]$ and $u(\cdot)$ is a strictly increasing, concave function and is twice continuously differentiable. For much of what follows, we assume a CES form:

(4) $\quad u(x)=\frac{x^{1-\sigma}}{1-\sigma} ; \quad \sigma>0$.

The commonly-agreed yardstick for welfare is $U\left(c_{y}, c_{m}, c_{o}\right)$, the lifetime utility of the young self. This is the criterion used by the government as well.

\subsection{Present bias}

Notice, the subjective discount factor used by the young to compare middle and old age payoffs is $\delta \in(0,1)$. However, the subjective discount factor used by the middle self to compare those same payoffs is $\beta \delta<\delta$ where $\beta \in(0,1)$. If $\beta \in(0,1)$, the agent engages in quasi-hyperbolic discounting. Intuitively, she has limited patience at the start and shows a preference for living in the present; but she still values patience and expects to be more patient in the future. $\beta$ measures the degree of time inconsistency: as $\beta \rightarrow 1$, time inconsistency disappears. In other words, these preferences embed the special case of standard, exponential discounting when $\beta=1$. This is what O’Donoghue and Rabin (1999) call the "present-bias effect".

\subsection{Sophistication and naivete}

Is the agent aware of her impending time inconsistency? The literature usually studies the polar cases, sophisticated (naive) agents who are fully aware (totally unaware). To incorporate more generality, we follow O'Donoghue and Rabin (2001) and allow agents to be partially sophisticated: they are aware of the time inconsistency of their future selves but are unsure about the magnitude of the problem. Specifically, the young self expects the middle self to use the discount factor $\beta^{E} \delta$ (We use the superscript, $E$, to denote the expectation formalized by the young self.)

and $\beta^{E} \delta$ is a weighted average of the correct discount factor, $\beta \delta$, and the one the naive young self expects, $\delta$, i.e.,

(5) $\beta^{E} \delta \equiv[\alpha \beta+(1-\alpha)] \delta, \alpha \in[0,1]$

full naive: $\delta$

fully sophisticated: $\beta \delta$

where $\alpha$ is a measure of her sophistication level. When agents are partially sophisticated, the young self believes that the middle self will use a discount factor $\beta^{E} \delta$ to make decisions, when in fact, the middle self will make her decisions based on $\beta \delta$. In a sense, $\alpha$ is a measure of the young 
self's "behavioral flaw"; the lower $\alpha$ is, the worse the flaw. (Alternatively, $\alpha$ is a measure of her "ignorance" of her true future selves.) The agent is fully naive when $\alpha=0\left(\beta^{E}=1\right)$, partially sophisticated when $\alpha \in(0,1)\left(\beta^{E} \in(\beta, 1)\right)$ and fully sophisticated when $\alpha=1\left(\beta^{E}=\beta\right)$. In the language of O'Donoghue and Rabin (1999), $\alpha$ is a measure of the "sophistication effect", which as they point out, is clearly distinct from the present-bias effect. Fully naive people, for instance, are influenced solely by the present-bias effect.

A quick reminder before we go on. Agents within a cohort are identical, meaning, specifically, there is no heterogeneity in either $\alpha$ or $\beta$. In places below, we may be loose in our exposition and use phrases such as "this result holds for agents with $\beta<\tilde{\beta}$, those who are sufficiently present biased". What we will mean is "this result holds for a $\beta$-economy, one where every agent is sufficiently present biased having been endowed with a $\beta<\tilde{\beta}$ ".

\section{Economy with complete markets}

In a complete-markets economy, all agents can access a capital market where the gross return on borrowing and saving is $R(>1)$, exogenously given. Any borrowing or saving is for consumption purposes only. Denoting agents' financial assets in youth and middle age by $\left(a_{y}, a_{m}\right)$, the lifecycle per-period budget constraints for an agent are

(6) $c_{y}+a_{y}=\omega_{y}$,

(7) $c_{m}+a_{m}=\omega_{m}+a_{y} R$,

(8) $c_{o}=\omega_{o}+a_{m} R$,

where $a_{y}$ and $a_{m}$ are allowed to be negative. The intertemporal budget constraint under complete markets is

$$
c_{y}+\frac{c_{m}}{R}+\frac{c_{o}}{R^{2}}=\omega_{y}+\frac{\omega_{m}}{R}+\frac{\omega_{o}}{R^{2}} \equiv Y .
$$

This means $a_{y} \in\left(-\omega_{y}-\omega_{m} / R-\omega_{o} / R^{2}, \omega_{y}\right)$. That is the young cannot borrow more than the present value of the whole lifecycle income and can save at most up to the amount of the present endowment $\omega_{y}$. Similarly, given an $a_{y}, a_{m} \in\left(a_{y} R-\omega_{m}-\omega_{o} / R, \omega_{m}+a_{y} R\right)$. These constitute natural limits on borrowing/saving arising purely from the model restriction that all debts be cleared by the time the three periods are up. ${ }^{8}$ No lender restricts debt as long as these minimal natural limits are met. As such, one can think of this economy as representing the pre-CPFB scenario.

Even in this setting with unfettered credit markets, agents' perceptions of their future selves will critically matter for asset demands at various ages. A naive agent understands her own present bias but fails to recognize the same in her future self. Not so with the sophisticated. Next,

\footnotetext{
${ }^{8}$ These are no different than analogous restrictions on portfolio (bond) holdings needed to rule out Ponzi schemes.
} 
we take up the decision problem of a fully naive $(\alpha=0)$ young agent. We believe it is instructive to study this case in isolation before proceeding to study the case of partially sophisticated (naive) agents, $\alpha \in(0,1)$.

\subsection{Naive agent's problem}

A fully naive young agent $(\alpha=0)$ expects her future selves to blindly follow the plans she lays out for them. She chooses the optimal lifecycle plan by maximizing (1) subject to (6)-(8). The first order conditions are

$$
\begin{aligned}
& u^{\prime}\left(\omega_{y}-a_{y}^{*}\right)=\underbrace{\beta \delta} R u^{\prime}\left(\omega_{m}-a_{m}^{*}+a_{y}^{*} R\right), \\
& u^{\prime}\left(\omega_{m}-a_{m}^{*}+a_{y}^{*} R\right)=\underbrace{\delta} R u^{\prime}\left(\omega_{o}+a_{m}^{*} R\right),
\end{aligned}
$$

where $\left(a_{y}^{*}, a_{m}^{*}\right)$ are the interior optimal asset demands from the point of view of the naive young. Notice, the young uses a discount factor $\beta \delta$ herself but believes her middle self will use $\delta$, when in fact, the latter will use $\beta \delta$. The zero private-saving corner during youth and middle-age are defined by

(11) $u^{\prime}\left(\omega_{y}\right)>\beta \delta R u^{\prime}\left(\omega_{m}-a_{m}^{*}\right)$ for $a_{y}=0$

(12) $u^{\prime}\left(\omega_{m}+a_{y}^{*} R\right)>\delta R u^{\prime}\left(\omega_{o}\right)$ for $a_{m}=0$

respectively. The young borrows if $a_{y}^{*}<0$, and saves if $a_{y}^{*}>0$. Note $a_{m}^{*}$ is what the naive young wants her middle-aged self to choose, not realizing the latter will not comply due to the timeinconsistent preference. For (4), the optimal asset demand for the naive young is

$$
a_{y}^{*}=\frac{\omega_{y}\left[R+(\delta R)^{\frac{1}{\sigma}}\right](\beta \delta R)^{\frac{1}{\sigma}}-\omega_{m} R-\omega_{o}}{\left[R+(\delta R)^{\frac{1}{\sigma}}\right](\beta \delta R)^{\frac{1}{\sigma}}+R^{2}}
$$

and the same she plans for her middle-aged self is

$$
a_{m}^{*}=\frac{(\beta \delta R)^{\frac{1}{\sigma}}\left(R \omega_{y}+\omega_{m}\right)-\omega_{o} \Omega_{1}}{(\beta \delta R)^{\frac{1}{\sigma}}+R \Omega_{1}}
$$

where $\Omega_{1} \equiv \beta^{\frac{1}{\sigma}}+\left[R+R^{2}(\delta R)^{-\frac{1}{\sigma}}\right] /\left[R+(\delta R)^{\frac{1}{\sigma}}\right]>0$.

It is easy to show

$$
\frac{\partial a_{y}^{*}}{\partial \beta}>0
$$

Notice $\beta$ serves a dual purpose here - see Salanie and Treich (2009). Larger $\beta$ means the young values future consumption more, hence saves more, the standard story. But higher $\beta$ also means 
the present bias effect is weaker.

We next consider the naive agent's problem at middle age. She has carried youthful debt, $a_{y}^{*} R$, pre-determined, into middle age, but her preference over middle and old age consumption is (2), no longer (1): she takes $a_{y}^{*}$ as given and maximizes (2) subject to (7) and (8). Then the middle-aged agent's actual optimal asset demand, $a_{m}\left(a_{y}, \beta\right)$, a function of youthful debt, $a_{y}$, and degree of middle self's present bias, $\beta$, solves

$$
u^{\prime}\left(\omega_{m}-a_{m}+a_{y} R\right) \equiv \beta \delta R u^{\prime}\left(\omega_{o}+a_{m} R\right)
$$

which, for (4), is

$$
a_{m}\left(a_{y}, \beta\right)=\frac{\left(\omega_{m}+a_{y} R\right)(\beta \delta R)^{\frac{1}{\sigma}}-\omega_{o}}{R+(\beta \delta R)^{\frac{1}{\sigma}}}
$$

Denote by $a_{m}^{N, *}$ the actual middle-age asset demand of the naive $(N)$ where $a_{m}^{N, *} \equiv a_{m}\left(a_{y}^{*}, \beta\right)$ and it is obvious

$$
a_{m}^{N, *} \leq a_{m}^{*}
$$

The actual middle-age consumption (asset demand) of the naive agent is larger (smaller) than what the young agent plans for her future selves. Using (13), we have

$$
a_{m}^{N, *}=\frac{(\beta \delta R)^{\frac{1}{\sigma}}\left(R \omega_{y}+\omega_{m}\right)-\omega_{o} \Omega_{2}}{(\beta \delta R)^{\frac{1}{\sigma}}+R \Omega_{2}}
$$

where $\Omega_{2} \equiv 1+\left[R+R^{2}(\beta \delta R)^{-\frac{1}{\sigma}}\right] /\left[R+(\delta R)^{\frac{1}{\sigma}}\right]>0$.

To summarize, the naive agent when young lays out the lifecycle plan $\left(a_{y}^{*}, a_{m}^{*}\right)$, but due to the subsequent preference change, the actual choice of the agent turns out to be $\left(a_{y}^{*}, a_{m}^{N, *}\right)$, which implies the agent eventually overconsumes in middle age. This is illustrated in Figure $1 .{ }^{9}$ Notice, the figure is drawn for $\alpha=0$ (fully naive, no sophistication effect). In addition, as $\beta \rightarrow 1$, the present-bias effect vanishes and the orange and green lines merge: the point where they merge is the optimal choice of the exponential discounter.

\footnotetext{
${ }^{9}$ In this and all subsequent figures, we set $R=1.5, \omega_{y}=2, \omega_{m}=5, \omega_{o}=1, \sigma=2$ and $\delta=0.8$.
} 


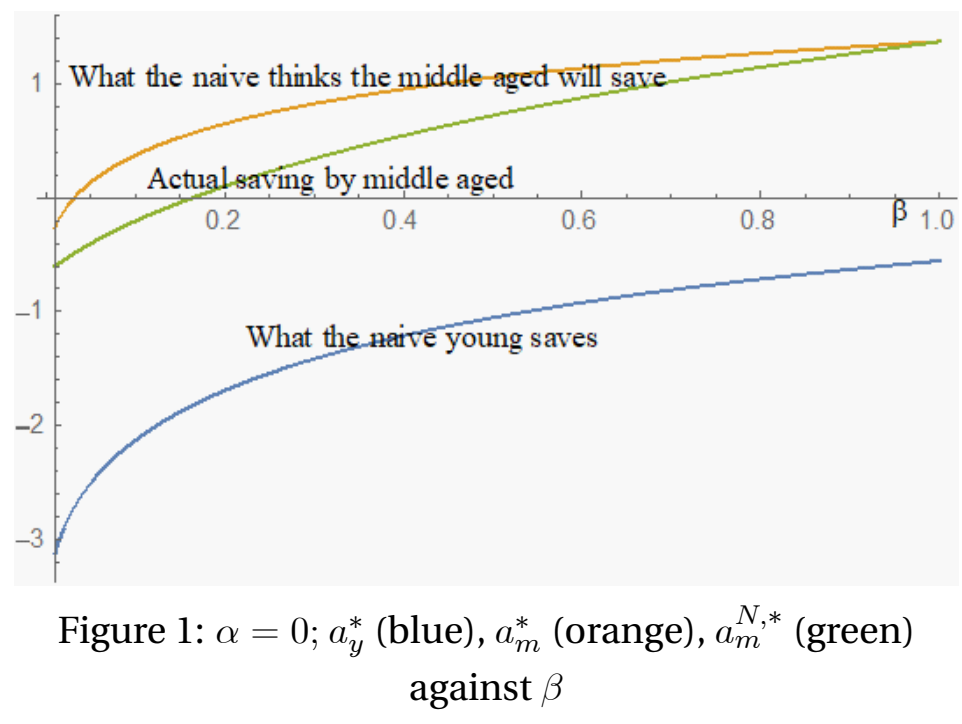

Without loss of generality, in all that follows, we assume for all $\beta$,

$$
\omega_{y}<\frac{\omega_{m} R+\omega_{o}}{\left[R+(\delta R)^{\frac{1}{\sigma}}\right](\beta \delta R)^{\frac{1}{\sigma}}}
$$

which ensures the young always borrow, the realistic case from a lifecycle perspective since the young are natural borrowers. ${ }^{10}$

\section{2 (Partially) sophisticated agent's problem}

Next, we consider a partially sophisticated (equivalently, partial naive) agent - when young, she is "somewhat" aware that her future, middle-age self will wish to deviate from the plans she lays out for them. Therefore, when choosing her youthful asset demand, $a_{y}^{S, *}$, she incorporates her perception of the anticipated behavior deviation of her future self by using the discount factor, $\beta^{E}$. (We use the superscript, $S$, to denote allocations chosen by a sophisticated agent.) Taking $a_{y}^{S, *}$ as predetermined, the middle-aged agent actually chooses $a_{m}^{S, *}$ using the right discount factor, $\beta \delta$. Notice, we are about to describe a scenario in which both the present bias and the sophistication effect arise.

\subsubsection{Optimal asset demands}

We go on to derive perception-perfect equilibria - O'Donoghue and Rabin (2001) - of the Stackelberg game between a partially sophisticated agent and her future selves. The idea is to use backward induction: figure out the young self's asset demand under her perception of her middle-

\footnotetext{
${ }^{10}$ Coeurdacier et al. (2015) present compelling evidence that, around the world, consumers tend to be net borrowers before reaching middle age.
} 
aged self's reaction to her choices. To that end, taking the youthful asset demand, $a_{y}$, as parametric, we derive the optimal (from the young's view point) middle-age asset demand, $a_{m}\left(a_{y}, \beta^{E}\right)$ by maximizing

$$
U\left(c_{m}, c_{o}\right)=u\left(c_{m}\right)+\underbrace{\beta^{E}} \delta u\left(c_{o}\right)
$$

subject to (7) and (8). We have

$$
a_{m}\left(a_{y}, \beta^{E}\right)=\frac{\left(\omega_{m}+a_{y} R\right)\left(\beta^{E} \delta R\right)^{\frac{1}{\sigma}}-\omega_{o}}{R+\left(\beta^{E} \delta R\right)^{\frac{1}{\sigma}}}
$$

$a_{m}\left(a_{y}, \beta^{E}\right)$ is equivalent to the expression for $a_{m}\left(a_{y}, \beta\right)$ (see eq. (15)) by substituting $\beta^{E}$ for $\beta$. Notice $a_{m}\left(a_{y}, \beta^{E}\right)$ is what the young, partially-sophisticated self expects her future middle-aged self to save given her own belief, $\beta^{E}$; this is her perception of the reaction (function) of her middle self to the $a_{y}$ she chooses.

Recall $\beta^{E} \equiv[\alpha \beta+(1-\alpha)]$. This means, ceteris paribus, $\beta^{E}$ rises with $\beta$ and falls with $\alpha$. Also, notice $\beta^{E} \delta$ is the weight a young self believes her middle self will place on the latter's future utility. It is also the young agent's perception of the effective present bias of her middle-aged self. Put together, these statements imply that lower the time consistency (i.e., higher the $\beta$ ), the higher is $\beta^{E}$ and lower is the perceived future self's present bias; but higher the level of sophistication, the lower is $\beta^{E}$ and higher is the perceived middle self's present bias.

By substituting $a_{m}\left(a_{y}, \beta^{E}\right)$ into the youthful preference, (1), we have

$$
V_{y}\left(a_{y}, \beta^{E}\right)=u\left(c_{y}\right)+\beta \delta\left[u\left(c_{m}\right)+\delta u\left(c_{o}\right)\right]=\frac{\left(\omega_{y}-a_{y}\right)^{1-\sigma}}{1-\sigma}+\underbrace{\beta \delta \Phi\left(\beta^{E}\right)} \frac{\left[\left(\omega_{m}+a_{y} R\right) R+\omega_{o}\right]^{1-\sigma}}{1-\sigma},
$$

where

$$
\Phi\left(\beta^{E}\right) \equiv \frac{1+\delta\left(\beta^{E} \delta R\right)^{\frac{1-\sigma}{\sigma}}}{\left[R+\left(\beta^{E} \delta R\right)^{\frac{1}{\sigma}}\right]^{1-\sigma}} .
$$

The term in equation (19), $\left(\omega_{m}+a_{y} R\right) R+\omega_{o}$, is the old-age value of the total wealth the agent owns at middle age. Note, $\Phi\left(\beta^{E}\right)=1+\delta$ for $\sigma=1$ (log utility). Also note, $\beta \delta \Phi\left(\beta^{E}\right)$ is the combined weight on future utility. All else same, if that weight increases, the effective present bias of the young is reduced. We collect some properties of $\Phi\left(\beta^{E}\right)$ and the weight, $\beta \delta \Phi\left(\beta^{E}\right)$, in the lemma below. 
Lemma $1 a$.

$$
\Phi^{\prime}\left(\beta^{E}\right)=\left(\frac{1-\sigma}{\sigma}\right) \underbrace{\frac{\left(1 / \beta^{E}-1\right)(\delta R)^{\frac{1}{\sigma}}\left(\beta^{E}\right)^{\frac{1-\sigma}{\sigma}}}{\left[R+\left(\beta^{E} \delta R\right)^{\frac{1}{\sigma}}\right]^{2-\sigma}}}_{\geq 0}\left\{\begin{array}{l}
<0 ; \sigma>1 \\
=0 ; \sigma=1 \\
>0 ; \sigma<1
\end{array},\right.
$$

$$
\Phi\left(\beta^{E}\right)+\beta \Phi^{\prime}\left(\beta^{E}\right)>0
$$

$b$.

$$
\begin{aligned}
& \frac{\partial\left(\beta \delta \Phi\left(\beta^{E}\right)\right)}{\partial \beta}=\delta\left[\Phi\left(\beta^{E}\right)+\alpha \beta \Phi^{\prime}\left(\beta^{E}\right)\right]>0 \\
& \frac{\partial\left(\beta \delta \Phi\left(\beta^{E}\right)\right)}{\partial \alpha}=\beta \delta\left[\Phi^{\prime}\left(\beta^{E}\right)(\beta-1)\right]\left\{\begin{array}{l}
>0 ; \sigma>1 \\
=0 ; \sigma=1 \\
<0 ; \sigma<1
\end{array}\right.
\end{aligned}
$$

What does this all mean? Recall $\beta^{E} \equiv[\alpha \beta+(1-\alpha)]$. This means, ceteris paribus, $\beta^{E}$ rises with $\beta$ and falls with $\alpha$. In words, given a sophistication level, the less the time-inconsistency (higher the $\beta$ ), higher the $\beta^{E}$; from (22), it implies a higher $\beta \delta \Phi\left(\beta^{E}\right)$ - a higher weight on future utility - and lower the effective present bias.

Now, hold time inconsistency $(\beta)$ fixed. Then, it follows from (23) that an increase in sophistication $(\alpha)$ raises $\beta \delta \Phi\left(\beta^{E}\right)$ when $\sigma>1$ which means a higher weight on future utility, lower the effective present bias (and hence, lower the tendency to overconsume in the current). But when $\sigma<1$, the opposite happens: the effective present bias is higher which means a higher tendency to overconsume in the current. This offers some intuition for why $\sigma$ is so crucial in what follows. For log utility, neither $\alpha$ nor $\beta$ has any effect on the weight to future utility: neither present bias nor sophistication matters for allocation choices in this case.

As the Stackelberg leader of the multi-selves game, the young will choose $a_{y}$ to maximize $V_{y}\left(a_{y}, \beta^{E}\right)$, the lifetime utility from her perspective. Her perspective can be more or less flawed depending on $\beta^{E}$, or indirectly, using (5), on $\alpha$. $V_{y}\left(a_{y}, \beta^{E}\right)$ denotes the flawed indirect utility of the young using the middle-age asset holding $a_{m}\left(a_{y}, \beta^{E}\right)$ (one that incorrectly uses $\beta^{E} \delta$ to discount the payoffs between middle and old age). When $\alpha=1$, the agent is fully sophisticated, we have $\beta^{E}=\beta$. Then $V_{y}\left(a_{y}, \beta\right)$ is the correct indirect utility taking the correct middle-age asset holding $a_{m}\left(a_{y}, \beta\right)$ into account, (the one that uses $\beta \delta$ as discount factor). That is, $V_{y}\left(a_{y}, \beta\right)$ is equivalent to substituting $a_{m}\left(a_{y}, \beta\right)$ - see eq. (15) - into the preference at youth (1) and therefore measures the actual lifetime welfare of the agent choosing $a_{y}$ at youth. 
The reaction function of the sophisticated young, $a_{y}^{S, *}$, is solved by $\partial V_{y}\left(a_{y}^{S, *}, \beta^{E}\right) / \partial a_{y}=0$ :

$$
\left.a_{y}^{S, *}\right|_{\alpha} \equiv a_{y}^{S, *}=\frac{\omega_{y}\left[\beta \delta R^{2} \Phi\left(\beta^{E}\right)\right]^{\frac{1}{\sigma}}-\omega_{m} R-\omega_{o}}{\left[\beta \delta R^{2} \Phi\left(\beta^{E}\right)\right]^{\frac{1}{\sigma}}+R^{2}}
$$

It can be verified that the fully naive's choice $\left.a_{y}^{S, *}\right|_{\alpha=0}=a_{y}^{*}$ (cf. (13)). Also, $\left.a_{y}^{S, *}\right|_{\alpha=1}$ is the fully sophisticated agent's optimal choice. For convenience of notation, we let $\left.a_{y}^{F, *} \equiv a_{y}^{S, *}\right|_{\alpha=1}$ in all of the following. (We use the superscript, $F$, to denote allocations chosen by a fully sophisticated agent.)

Notice, $a_{y}^{S, *}$, in general, involves $\sigma, \alpha$, and $\beta$. The effect of $\sigma$ is, in some sense, of first-order importance, since for $\sigma=1, \Phi\left(\beta^{E}\right)=1+\delta$ and $a_{y}^{S, *}$ becomes independent of $\alpha$ : for log utility, as noticed earlier, sophistication or lack thereof has no impact on asset demands. In fact, it is easy to check that for log utility, $a_{y}^{*}=a_{y}^{S, *}$ (the naive and the sophisticated agent choices are identical, irrespective of $(\alpha, \beta)$ ). The curvature of $u$ captures the ease or hesitation with which an agent is willing to substitute current for future consumption. The naive undertakes such substitution on her own terms and blissfully ignores the effect of her decisions on her future selves; not so with the sophisticated. The latter saves an extra \$1 on the margin to endow the middle-aged \$1 extra wealth. The middle-aged can now borrow more to satisfy her present biased consumption, an income effect. But doing so raises the relative marginal utility of old-age consumption (compared to the marginal utility of middle-age consumption), causing him to save some of this extra wealth to help finance old-age consumption, a substitution effect. For log utility, these two effects cancel out: on net, sophistication, under log utility, brings no advantages whatsoever.

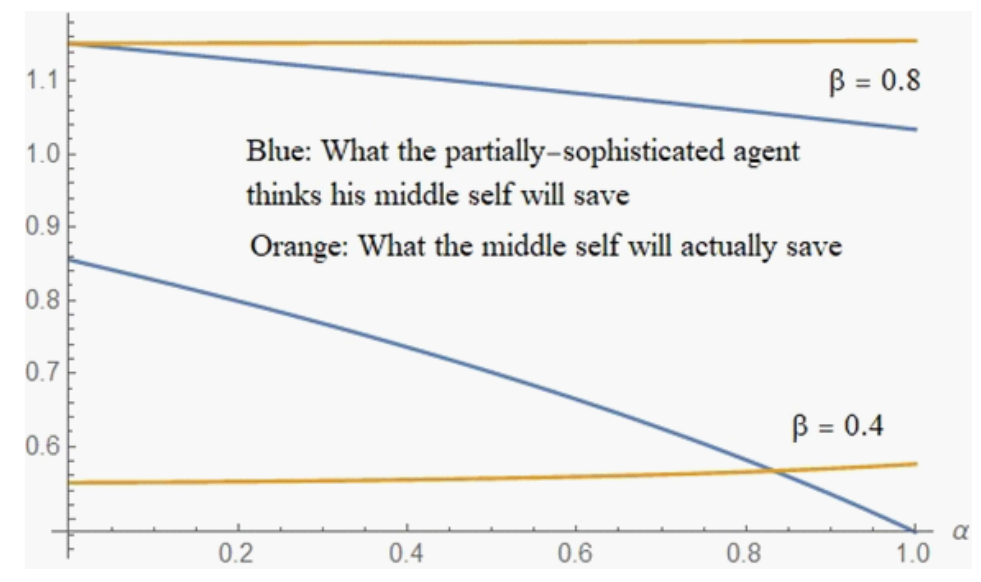

Figure 2: Middle-age savings against $\alpha$

What about the middle-aged self? Given $a_{y}^{S, *}$, the optimal asset holding for the middle aged who correctly discounts future old-age utility by $\beta \delta$, is $a_{m}^{S, *}=a_{m}\left(a_{y}^{S, *}, \beta\right)$, and hence, the actual lifetime welfare of the agent is $V_{y}\left(a_{y}^{S, *}, \beta\right)$. That is, $a_{m}^{S, *}$ is derived by using the expression for 
$a_{m}\left(a_{y}, \beta\right)$ (see eq. (15)), substituting $a_{y}^{S, *}$ for $a_{y}$. The above figure sets $\beta=0.4$ (i.e., holds the present bias effect constant) and studies the sophistication effect. The gap between actual and "imagined" saving is the highest for the fully naive and is reduced with increased sophistication.

\subsubsection{Impact of time inconsistency and sophistication on asset demands}

Next, we study how the sophisticated young strategically chooses her asset holding to combat future undesired deviations. We wish to understand how the sophistication level, $\alpha$, and time inconsistency, $\beta$, play into her decisions. Recall, the sophisticated young discounts payoffs between young and middle age by $\beta \delta$, and the payoffs between middle and old age by $\beta^{E} \delta$.

Lemma 2 a. For a given $\alpha \in[0,1]$,

(25) $\frac{\partial a_{y}^{S, *}}{\partial \beta}=\frac{d a_{y}^{S, *}}{d\left(\beta \Phi\left(\beta^{E}\right)\right)}\left[\Phi\left(\beta^{E}\right)+\beta \Phi^{\prime}\left(\beta^{E}\right)\right]>0$,

and

b. For a given $\beta, d a_{y}^{S, *} / d \Phi>0, d \beta^{E} / d \alpha=-(1-\beta) \delta<0$ holds, implying

(26) $\frac{\partial a_{y}^{S, *}}{\partial \alpha}=-(1-\beta) \delta \frac{d a_{y}^{S, *}}{d \Phi} \Phi^{\prime}\left(\beta^{E}\right) \gtreqless 0$, for $\sigma \gtreqless 1$.

The proof is a straightforward application of Lemma 1. Notice, (25) implies the optimal asset holding of the young decreases in the level of time inconsistency because she always undervalues future payoffs during youth and middle age causing her to reduce her asset holding when young. (26) means, when $\sigma>1$, the sophisticated young will save more than her fully naive counterpart. Also, the optimal youthful asset holding of the partially sophisticated agent is monotonically increasing (decreasing) in her sophistication level, i.e.,

\section{Proposition 1}

$$
\begin{aligned}
& \left.a_{y}^{*} \equiv a_{y}^{S, *}\right|_{\alpha=0}<\left.a_{y}^{S, *}\right|_{\alpha \in(0,1)}<\left.a_{y}^{S, *}\right|_{\alpha=1} \equiv a_{y}^{F, *}, \quad \sigma>1 \\
& \left.a_{y}^{*} \equiv a_{y}^{S, *}\right|_{\alpha=0}>\left.a_{y}^{S, *}\right|_{\alpha \in(0,1)}>\left.a_{y}^{S, *}\right|_{\alpha=1} \equiv a_{y}^{F, *}, \quad \sigma<1 .
\end{aligned}
$$

From the perspective of the sophisticated young, her middle-aged self consumes too much (saves too little, hence has too little old-age consumption). As such, any mechanism that delivers less consumption in middle age and more in old age is welcome from her perspective. The problem is, she has only one instrument at her disposal: her own asset holding. If she raises it (possibly, reduces her borrowing), middle-aged wealth rises; some of this is used by the middleaged to raise consumption but the remainder is passed on as higher wealth to the old. The latter effect is desirable but not the former. In short, the simultaneous reduction in middleage consumption and increase in old-age consumption, while desirable from the young self's 
perspective, is not possible using the one tool she has, her youthful asset holding. (She needs some help but the unfettered nature of the market precludes it.) When $\sigma>1$, agents would substitute out of middle into old-age consumption: in this case, increasing old-age consumption is more salient to her, and therefore, as $\alpha$ increases - the more sophisticated the agent - the more she would increase her youthful asset holding to increase future old-age consumption. Vice versa for the case $\sigma<1$.

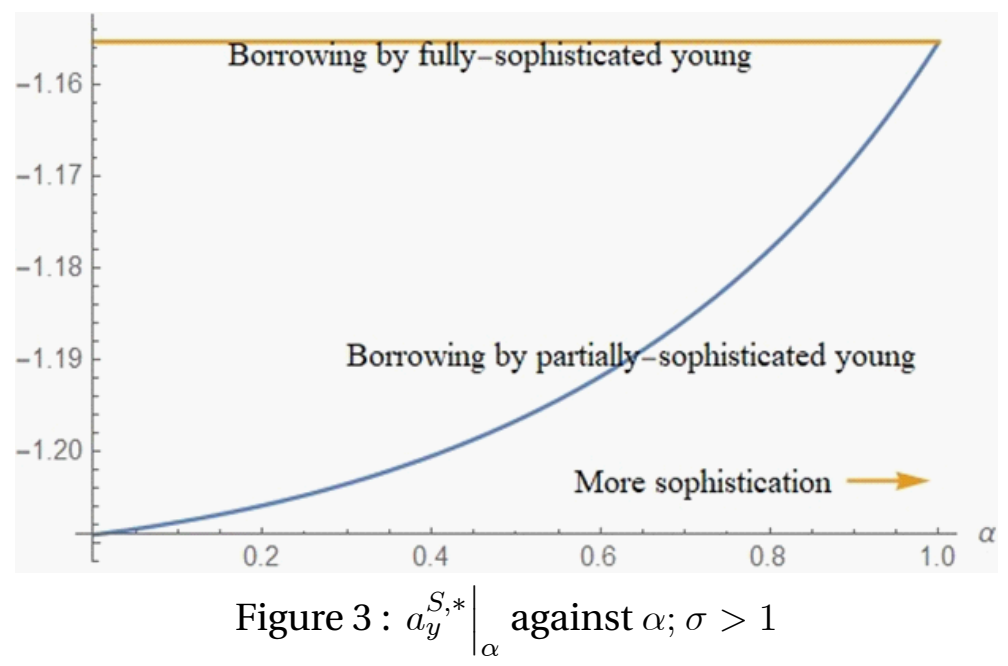

From the standpoint of the young, the committed (or the fully naive) solution $\left(a_{y}^{*}, a_{m}^{*}\right)$ would be first best. However, because of time inconsistency, this is unachievable sans further intervention even if the agent is fully sophisticated. ${ }^{11}$ It is evident that, ex post, the young always prefer solutions that use future discount rates in a sophisticated manner. Henceforth, we refer to the choices of a fully sophisticated agent as second-best. The welfare ranking of different asset choices is given in the proposition below. It needs to be noted that the welfare of the young agent monotonically increases in her sophistication level.

\section{Proposition 2}

$$
\left.\left.\left.\left(a_{y}^{*}, a_{m}^{*}\right) \succ\left(a_{y}^{S, *}, a_{m}^{S, *}\right)\right|_{\alpha=1} \equiv\left(a_{y}^{F, *}, a_{m}^{F, *}\right) \succ\left(a_{y}^{S, *}, a_{m}^{S, *}\right)\right|_{\alpha \in(0,1)} \succ\left(a_{y}^{S, *}, a_{m}^{S, *}\right)\right|_{\alpha=0} \equiv\left(a_{y}^{*}, a_{m}^{N, *}\right)
$$

As discussed, when $\sigma>1$, partially sophisticated agents borrow too much compared to their fully sophisticated counterparts. That opens up the possibility that imperfections in the credit market, those that prevent borrowing (and hence, overborrowing!) may indeed help some agents. We take this up in the next section.

\footnotetext{
${ }^{11}$ Del Rey and Lopez-Garcia (2019) reach a very similar conclusion.
} 


\section{An economy with borrowing constraints}

We proceed to investigate an economy in which the CFPB regulates borrowing based on an ability-to-repay rule. This means, the CFPB dictates lenders to lend only to the extent a borrower can repay. ${ }^{12}$ To make the problem interesting, inspired by Kehoe and Levine (1993) and Azariadis and Lambertini (2003), here on we posit that agents are strategic about repaying their loans: they weigh the costs and benefits from default. The penalty for (or opportunity cost of) default is total exclusion from credit markets thereafter and seizure of all tangible assets but not her private, inalienable endowments. (Think of this as consumer bankruptcy.) Such a severe penalty thwarts consumption smoothing and, is hence, a deterrent against default for some. The CPFB (and the lenders) are aware of this default calculus and screen (impose limits on) the amounts a person can borrow. This limit prevents "overborrowing" (from the lender's perspective) and eliminates default. What makes the subsequent analysis extra interesting and challenging is that a) agents are (partially) naive and could benefit from external help, and b) their naivete may exacerbate any existing desire to "overborrow" and subsequently default. The CFPB's ability-to-repay rule may be able to help with both. ${ }^{13}$

Since the CFPB is a governmental entity, we assume it is benevolent and uses the welfare of the sophisticated young as its yardstick for policy interference. This is consistent with the idea that naivete is a behavioral mistake and may lead to 'overborrowing' and it is the government's job to help such people. The CFPB is paternalistic because it uses the utility of the fully sophisticated young to tell others how to behave or prevent people from making behavioral mistakes.

A word about default. Under perfect information, lenders set the borrowing limit at an amount that balances the costs and benefits of default. It is in the borrower's self interest to repay any loan that is less than this borrowing limit; as such, default never occurs in equilibrium. For this reason, as we will see, agents face the same interest rate independently of their income and debt levels. ${ }^{14}$

\footnotetext{
${ }^{12}$ Zhang (1997) assumes "that there exists an outside agency that knows the investor's problem. The agency plays no role other than in setting up and enforcing the borrowing limits. Should an investor default on his debt, the agency would exclude him from intertemporal asset trading forever." The CFPB is that agency.

${ }^{13}$ Sometimes, researchers use the term "full commitment economy" to describe what we have called the "complete markets economy". What they mean is that in the complete markets economy, all agents can fully commit to repaying their loans. By the same token, the incomplete commitment economy is what we call the "borrowing-constrained economy" because borrowers can strategically default, meaning there is no ex ante commitment to repay loans taken on by past selves. We avoid the term "commitment" in this context because we save it to differentiate between the naive and the sophisticated: the former incorrectly believe they can commit to their future plans while the latter realize they have no commitment power.

${ }^{14}$ In the data, lenders use both the interest rate and the credit constraints to separate borrowers, since agents may have different (non-zero) default probabilities. Abraham and Carceles-Poveda (2010) argue that, nevertheless, a model with no default is in line with U.S. data in terms of its predictions regarding how the borrowing limits and (labor) income are related.
} 


\subsection{Borrowing limits}

Lenders are instructed by the CFPB to apply the ability-to-repay rule. Recall, the CFPB uses agents' actual discount factor between middle and old age, $\beta \delta .{ }^{15}$ (Below, we show that were the CFPB to use the discount factor, $\beta^{E} \delta$, the same as used by borrowers, all borrowers will default on their youthful debt upon reaching middle age.) Suppose the young agent cannot borrow more than $\left(-\bar{a}_{y},-\bar{a}_{m}\right)$ in youth and middle age,

$$
\begin{aligned}
a_{y} & \geq \bar{a}_{y} \\
a_{m} & \geq \bar{a}_{m} .
\end{aligned}
$$

Clearly $\left(\bar{a}_{y}, \bar{a}_{m}\right)$ should satisfy the following individual rationality constraints (IRC):

$$
\begin{aligned}
u\left(c_{m}\right)+\beta \delta u\left(c_{o}\right) & \geq u\left(\omega_{m}\right)+\beta \delta u\left(\omega_{o}\right), \\
u\left(c_{o}\right) & \geq u\left(\omega_{o}\right) .
\end{aligned}
$$

These two IRCs amounts to self-enforcement of loan contracts: creditors should always offer a loan of a size sufficient to ensure that borrowers will always prefer repayment to default at middle age. IRC(2) means middle-aged agents are not allowed to borrow. This is because credit market participation at that age has no value for them in old age leaving them with no reason to repay their debts. It is evident that IRC(2) is equivalent to

$$
\text { (29) } a_{m} \geq 0
$$

which solves the borrowing limit for middle-aged agents, i.e., $\bar{a}_{m}=0$.

The borrowing limit for the young is more complicated. Young borrowers carry debts $a_{y} R$ and an utility function (2) into middle age. If the middle-aged agent repays the debts of her youth, she can continue to trade in the credit market and has the following value function:

$$
\begin{gathered}
V_{m}\left(a_{y}\right) \equiv \max _{\left\{a_{m}\right\}}\left\{u\left(\omega_{m}+a_{y} R-a_{m}\right)+\beta \delta u\left(\omega_{o}+a_{m} R\right)\right\} \\
\text { s.t. } a_{m} \geq 0,
\end{gathered}
$$

where, at an optimum, $a_{m}=a_{m}\left(a_{y}, \beta\right)$. Otherwise, she is excluded from the credit market and in autarky, that is, $\left(c_{m}, c_{o}\right)=\left(\omega_{m}, \omega_{o}\right)$. As previously discussed, the CFPB imposes a borrowing limit that renders borrowers indifferent between autarky and market participation in middle age. Hence, by defining

$$
H\left(a_{y}\right) \equiv V_{m}\left(a_{y}\right)-u\left(\omega_{m}\right)-\beta \delta u\left(\omega_{o}\right)
$$

\footnotetext{
${ }^{15}$ The assumption is also reasonable if one assumes that a practice of repeat lending to many will eventually alert lenders to the true preferences of their clients.
} 
the borrowing limit for the young is determined by

$$
H\left(\bar{a}_{y}\right)=0
$$

Given the definition of $\bar{a}_{y}$, it is evident that the middle-aged agent will default on her youthful debt if and only if she borrows more than $-\bar{a}_{y}$ in her youth. It is easy to show that the borrowing limit, $-\bar{a}_{y}$, for the young monotonically increases in $\beta$,

$$
\frac{\partial\left(-\bar{a}_{y}\right)}{\partial \beta}=\frac{\partial H / \partial \beta}{\partial H / \partial \bar{a}_{y}}=\frac{\delta u\left(\omega_{o}+a_{m} R\right)-\delta u\left(\omega_{o}\right)}{R u^{\prime}\left(\omega_{m}+a_{y} R-a_{m}\right)} \geq 0 .
$$

Large $\beta$ means the borrower has a stronger incentive to save when middle aged, and therefore, a stronger incentive to avoid autarky allowing creditors to lend more. Also notice, since $\beta^{E} \geqslant \beta$ and $\partial\left(-\bar{a}_{y}\right) / \partial \beta>0$, creditors (or the CFPB), were they to lend according to the incorrect naive beliefs $\beta^{E}$, would "overlend" leading to rampant default on all youthful debt. For the CES utility function,

(33) $-\bar{a}_{y}=\frac{\omega_{m}}{R}+\frac{\omega_{o}}{R^{2}}-\frac{\left(\omega_{m}^{1-\sigma}+\beta \delta \omega_{o}^{1-\sigma}\right)^{\frac{1}{1-\sigma}} R^{\frac{2 \sigma-1}{1-\sigma}}}{\left[R+(\beta \delta R)^{\frac{1}{\sigma}}\right]^{\frac{\sigma}{1-\sigma}}}$,

which is independent of the agent's sophistication level, $\alpha$, since the loan decision is made with $\alpha=1$ ( $\beta^{E}=\beta$, full sophistication) in mind. Henceforth, $\left(-\bar{a}_{y},-\bar{a}_{m}\right)$ are termed the endogenous borrowing constraints (EBC).

\subsection{Borrowing-constrained asset demands}

Denote $a_{m}^{B, *}$ the solution to (30), the optimal asset demand for a middle-aged agent who has paid off her past debt. (We use superscript $B$ to denote borrowing-constrained.) By (29), it is evident that $a_{m}^{B, *} \geq 0$; no borrowing when middle aged. As standard in the literature, (32) shows that the young are not allowed to borrow, i.e., $\bar{a}_{y}=0$, if and only if $a_{m}^{B, *}=0$ (the middle-aged would have liked to borrow but are borrowing constrained by (29). Hence, we define a threshold value of $\beta$, call it $\beta_{L}$, such that for all $\beta \leq \beta_{L}$, the asset demands of young and middle-aged agents are simultaneously binding and equal to zero. More formally,

$$
u^{\prime}\left(\omega_{m}\right) \leq \beta \delta R u^{\prime}\left(\omega_{o}\right) \Longrightarrow \beta \geq \frac{u^{\prime}\left(\omega_{m}\right)}{\delta R u^{\prime}\left(\omega_{o}\right)} \equiv \beta_{L}
$$

This means the young can borrow (or lenders are allowed by the CFPB to lend to the young) only when every agent has $\beta \geq \beta_{L}$. ${ }^{16}$ By way of contrast, recall with complete credit markets, young agents with $\beta \in(0,1]$ could borrow. When $\beta \geq \beta_{L}$, the optimal asset demand of a middle-

\footnotetext{
${ }^{16}$ When $\beta \leq \beta_{L}, u^{\prime}\left(\omega_{m}\right) / u^{\prime}\left(\omega_{o}\right) \geq \beta \delta R$ holds, a middle-aged agent has no incentive to save even if she incurred no debt in her youth. In that case, an indebted middle-aged agent would always choose to default. Knowing this, creditors will not lend to the young, implying $\bar{a}_{y}=0$.
} 
aged agent with no prior borrowing is positive, i.e., $a_{m}^{B, *}>0$. In this case, defaulting is costly for middle-aged agents, and, as noted by (32), creditors can always choose a strictly positive borrowing limit which ensures the agent is indifferent between default and repayment.

Recall under complete markets, we have $\partial a_{y}^{S, *} / \partial \beta \geq 0$ (25) while from (33), the borrowing limit for the young, $\bar{a}_{y}$, is zero when $\beta \in\left(0, \beta_{L}\right]$ and monotonically decreases in $\beta$ when $\beta \in$ $\left[\beta_{L}, 1\right]$. Hence, the two curves $a_{y}^{S, *}(\beta)$ and $\bar{a}_{y}(\beta)$ must intersect (see Figure 4 for an example). Suppose they intersect at $\beta_{H}$. Then, there are three possible outcomes. 1) $\beta \in\left(0, \beta_{L}\right]$ : for $\beta$ in this range, everyone is borrowing constrained both in youth and in middle age. In this case, $\bar{a}_{y}=0$ and $a_{y}^{B, *}=a_{m}^{B, *}=0$, and the economy is in financial autarky with no activity in the credit market. 2) $\beta \in\left[\beta_{L}, \beta_{H}\right]$ : each agent is borrowing constrained but only when young. ${ }^{17}$ In this case, borrowing constraints are slack for middle-aged agents, with $a_{y}^{B, *}=\bar{a}_{y}<0$ and $a_{m}^{B, *} \equiv a_{m}\left(\bar{a}_{y}, \beta\right)>0$. 3) $\beta \geq \beta_{H}$ : both borrowing constraints are slack, yielding CM solutions, $\left(a_{y}^{S, *}, a_{m}^{S, *}\right)$. If $\beta_{H}>1$, we do not have the last case. ${ }^{18}$

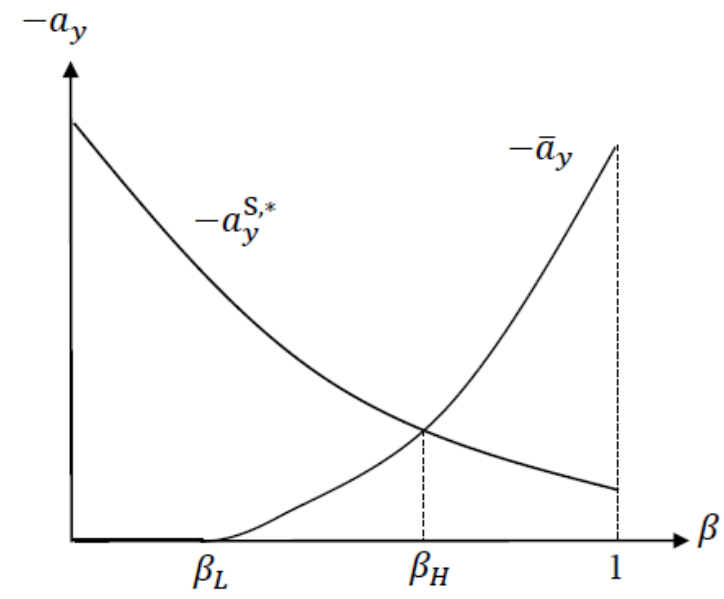

Figure 4: Asset demand of the young agent

We finally can define optimal asset demands, $\left(a_{y}^{B, *}, a_{m}^{B, *}\right)$, in a way that respect the IRCs. Note that if $\bar{a}_{y}<a_{y}^{S, *}$, the borrowing constraint for a young agent is slack, and her optimal asset demand is equal to the CM solution. Young-age optimal asset demand is, thus, defined by

(34) $a_{y}^{B, *}=\max \left\{\bar{a}_{y}, a_{y}^{S, *}\right\}$.

\footnotetext{
${ }^{17} \beta_{H}$ cannot be smaller than $\beta_{L}$. Otherwise the young will be unconstrained even when the borrowing limit in youth is zero. This means under complete markets, the young want to save and not borrow for all $\beta \in\left[\beta_{H}, 1\right]$, which cannot be true under the assumption of (16).

${ }^{18}$ Notice that $\beta_{H}$ could be larger or smaller than $1 . \beta_{H} \leq 1$ if and only if $\left.a_{y}^{S, *}\right|_{\beta=1} \geq\left.\bar{a}_{y}\right|_{\beta=1}$, which after some tedious algebra is equivalent to $\omega_{y} \geq \underline{\omega_{y}}$ where

$$
\underline{\omega_{y}}=\left[\frac{\left(\omega_{m}^{1-\sigma}+\delta \omega_{o}^{1-\sigma}\right) R}{R+(\delta R)^{\frac{1}{\sigma}}}\right]^{\frac{1}{1-\sigma}} \frac{R(\delta R)^{\frac{1}{\sigma}}+(\delta R)^{\frac{2}{\sigma}}+R^{2}}{R^{2}(\delta R)^{\frac{1}{\sigma}}}-\frac{\omega_{m} R+\omega_{o}}{R^{2}} .
$$
}


Similarly, the optimal asset demand in middle age is

$$
a_{m}^{B, *}=\max \left\{0, a_{m}\left(a_{y}^{B, *}, \beta\right)\right\}
$$

\section{Welfare Impact of Endogenous Borrowing Constraints}

Since (1) is our welfare yardstick, the naive agents' optimal choices in youth and under complete markets, $\left(a_{y}^{*}, a_{m}^{*}\right)$ - see Section 3.1 - are the first-best solutions. Of course, as we have seen, naive or partially sophisticated agents do not follow previously made plans and would overconsume during middle age. This also means, without intervention from the government, agents on their own cannot achieve the first-best solutions in the complete market. What can they achieve? In other words, given the middle aged agent actually chooses $a_{m}\left(a_{y}, \beta\right)$ and not $a_{m}^{*}$, what is the maximum value of (1)? This is exactly the question fully sophisticated agents face. This means $V_{y}\left(a_{y}^{F, *}, \beta\right)$ is the highest lifetime welfare an agent can actually achieve in the complete market. That is, $V_{y}\left(a_{y}^{F, *}, \beta\right)>V_{y}\left(a_{y}, \beta\right)$ for all $a_{y} \neq a_{y}^{F, *}$. We refer to the optimal choices of the fully sophisticated agent, $\left(a_{y}^{F, *}, a_{m}^{F, *}\right)$, as the second-best solution.

Below, we explore whether EBC can improve the resource allocations and welfare of partially sophisticated agents by comparing their optimal asset demands in the complete market to the second best solutions. This seems counterintuitive since conventional wisdom suggests that any constraints on credit availability would impede consumption smoothing and thereby hurt agents. Not so, though, when agents are time inconsistent and prone to present bias. Can EBC help? To foreshadow, the answer is yes, and it depends on both $\beta$ and $\alpha$. Recall, from Section 2.3, the former is associated with the present-bias effect, and the latter with the sophistication effect.

\subsection{Present-bias effect}

We refer to results concerning (given agents' sophistication level $\alpha \in[0,1)$ ) how the degree of present-bias $\beta$ affect the welfare impacts of EBC as the present-bias effect. Recall, all agents are completely borrowing constrained with autarkic consumption when $\beta \in\left[0, \beta_{L}\right]$, partially borrowing constrained when $\beta \in\left[\beta_{L}, \beta_{H}\right]$ and completely unconstrained when $\beta \in\left[\beta_{H}, 1\right]$. This means, if agents are mildly time inconsistent, $\beta \in\left[\beta_{H}, 1\right]$, they would each freely choose the $\mathrm{CM}$ allocations, and therefore EBC can have no influence on their decisions and welfare. ${ }^{19}$ What about economies in which agents are significantly time-inconsistent, $\beta \in\left[0, \beta_{H}\right]$ ? Our flagship proposition reports on this issue. Recall, if $\sigma \leq 1$, the naive and partially sophisticated agents borrow "too little" during youth in the complete market and EBC cannot be welfare improving for them.

\footnotetext{
${ }^{19}$ Recall in the complete market, partially sophisticated agents may overborrow in youth if only if $\sigma>1$. Therefore, a necessary condition for EBC to be of some help is $\sigma>1$.
} 
Proposition 3 Suppose $\sigma>1$ so that naive and partially sophisticated agents borrow "too much". Given any sophistication level $\alpha \in[0,1)$, there exists a threshold degree of present bias, $\widehat{\beta} \in$ $\left(\beta_{L}, \beta_{H}\right)$, such that

1) if $\beta_{H} \leq 1$, EBC reduce their lifetime welfare for $\beta \in(0, \widehat{\beta}]$, increase it when $\beta \in\left[\widehat{\beta}, \beta_{H}\right]$ and have no impact on agents' lifetime welfare when $\beta \in\left[\beta_{H}, 1\right]$;

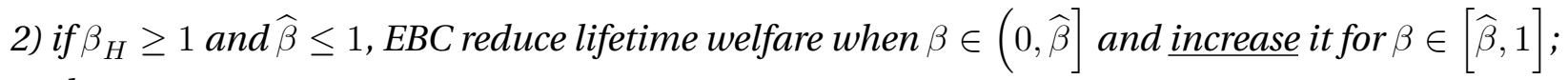
and

3) if $1 \leq \widehat{\beta} \leq \beta_{H}$, EBC always reduce lifetime welfare.

The upshot is that for economies with "intermediate" levels of time inconsistency, i.e., $\beta \in$ $\left[\widehat{\beta}, \min \left(\beta_{H}, 1\right)\right]$, EBC can help agents and even deliver higher welfare than under complete markets. EBC prevent young agents from borrowing too much, but if they are too tight, they may hurt the young by restricting their ability to smooth consumption across periods. It follows that EBC have two opposing effects on young agents' welfare. Since the borrowing limit imposed on the young, $-\bar{a}_{y}(\beta)$, is monotonically increasing in $\beta$, only when $\beta$ is close to $\beta_{H}$, i.e., $\beta \in\left[\widehat{\beta}, \beta_{H}\right]$, so that EBC are not too tight, the positive effect of EBC can dominate, improving welfare. Not only that. As shown in the proof for Proposition 3, EBC could further help everyone achieve the second best, $\left(a_{y}^{F, *}, a_{m}^{F, *}\right)$, in the economy where $\beta=\widehat{\beta}_{F}$ and $\widehat{\beta}_{F}$ solves $\bar{a}_{y}\left(\widehat{\beta}_{F}\right) \equiv a_{y}^{F, *}\left(\widehat{\beta}_{F}\right)$. When $\beta=\widehat{\beta}_{F}$, the borrowing limit imposed on the young agent exactly equals to the size of youthful loan the fully sophisticated agent would optimally borrow in the CM world. Notice, since $\widehat{\beta} \in\left(\beta_{L}, \beta_{H}\right)$, the welfare of everyone in the highest present bias economies, $\beta \in\left(0, \beta_{L}\right]$, who are also completely borrowing constrained, cannot be improved via EBC.

We move on to ask, given $\alpha$, how does the welfare gain generated by EBC, $\Delta V_{y}=V_{y}\left(\bar{a}_{y}, \beta\right)-$ $V_{y}\left(a_{y}^{S, *}, \beta\right)$, change with $\beta$. Here, we focus attention on case (1) of Proposition 3 where $\beta_{H} \leq 1$. Results for other scenarios are easily extended. From Proposition 3 and Figure 4, it is evident that the welfare gain of EBC is negative for $(0, \widehat{\beta}]$, i.e., $\Delta V_{y}<0$, but monotonically increases in $\beta$ as the absolute difference between EBC solution and CM solution, $\bar{a}_{y}-a_{y}^{S, *}$, monotonically decreases in $\beta$. Moreover, as shown in Proposition 3, the welfare gain of EBC is positive for $\left[\widehat{\beta}, \beta_{H}\right]$ and equals to zero for $\left[\beta_{H}, 1\right]$. These two statements, together with the continuity of $\Delta V_{y}$, imply an inverted U-shaped relationship between the welfare gain of EBC, $\Delta V_{y}$, and $\beta$. The following lemma shows how agents' sophistication level $\alpha$ affect the present-bias effect of EBC.

Lemma 3 If $\sigma>1, \widehat{\beta}\left(\beta_{H}\right)$ monotonically increases (decreases) in $\alpha$, i.e., $\partial \widehat{\beta} / \partial \alpha>0$ and $\partial \beta_{H} / \partial \alpha<$ 0 .

Proposition 3 shows that EBC can improve the welfare of naive and partially sophisticated agents in economies with $\beta \in\left[\widehat{\beta}, \min \left(\beta_{H}, 1\right)\right]$. Lemma 3 , however, shows that the welfare improving range $\left[\widehat{\beta}, \min \left(\beta_{H}, 1\right)\right]$ shrinks with sophistication implying EBC lose potency with increased sophistication. In the extreme, as agents become fully sophisticated, $\left[\widehat{\beta}, \min \left(\beta_{H}, 1\right)\right]$ shrinks to a singleton and EBC can no longer improve welfare for agents in any $\beta$ economy. 


\subsection{Sophistication effect}

We now proceed to explore how welfare impacts of EBC change in $\alpha$ for fixed $\beta$. Recall that $\widehat{\beta}_{F}$ is defined by $\bar{a}_{y}\left(\widehat{\beta}_{F}\right)=\left.a_{y}^{F, *}\left(\widehat{\beta}_{F}\right) \equiv a_{y}^{S, *}\left(\widehat{\beta}_{F}\right)\right|_{\alpha=1}$. Similarly define $\widehat{\beta}_{N}$ by $\bar{a}_{y}\left(\widehat{\beta}_{N}\right)=a_{y}^{*}\left(\widehat{\beta}_{N}\right) \equiv$ $\left.a_{y}^{S, *}\left(\widehat{\beta}_{N}\right)\right|_{\alpha=0}$. As shown in Figure 4, $\widehat{\beta}_{F}$ and $\widehat{\beta}_{N}$ are the two boundaries of intersections between the curve $\bar{a}_{y}(\beta)$ and the set of curves $\left.a_{y}^{S, *}(\beta)\right|_{\alpha \in[0,1]}$, and $\widehat{\beta}_{F}<\left.\beta_{H}\right|_{\alpha \in(0,1)}<\widehat{\beta}_{N}$. Notice, $\widehat{\beta}_{F}$ and $\widehat{\beta}_{N}$ are independent of $\alpha$. $\widehat{\beta}_{N}$ could be larger or smaller than 1 . For simplicity, we assume $\widehat{\beta}_{N}<$ 1 in the following proposition. The results for $\widehat{\beta}_{N} \geqslant 1$ can be easily extended as in Proposition 3 .

Proposition 4 Suppose $\sigma>1$.

(1) Consider an economy with $\beta<\widehat{\beta}_{F}$ where the agents are highly present biased, every naive and sophisticated agents are borrowing constrained, and therefore have to make same decisions $\bar{a}_{y}$. Then, there exists a threshold degree of sophistication, $\widehat{\alpha}_{1} \in[0,1)$, such that EBC improve the welfare of the less sophisticated agents endowed with $\alpha \in\left[0, \widehat{\alpha}_{1}\right]$, and reduce the welfare of more sophisticated agents endowed with $\alpha \in\left[\widehat{\alpha}_{1}, 1\right]$. Moreover the welfare gain generated by EBC, $\Delta V_{y}=V_{y}\left(\bar{a}_{y}, \beta\right)-V_{y}\left(a_{y}^{S, *}, \beta\right)$, monotonically decreases in $\alpha$ for $\alpha \in[0,1]$.

(2) If $\widehat{\beta}_{F} \leq \beta<\widehat{\beta}_{N}$ so that agents are intermediately present biased, there exists a threshold degree of sophistication, $\widehat{\alpha}_{2} \in(0,1)$, such that all agents endowed with $\alpha \in\left[0, \widehat{\alpha}_{2}\right]$ are borrowing constrained and have to make the same decisions $\bar{a}_{y}$, and all agents endowed with $\alpha \in\left[\widehat{\alpha}_{2}, 1\right]$ are unconstrained. EBC improve the welfare of the former, less sophisticated agents and have no impacts on the welfare of the latter, more sophisticated agents. Moreover, the welfare gain generated by EBC $\Delta V_{y}$ monotonically decreases in $\alpha$ for $\alpha \in\left[0, \widehat{\alpha}_{2}\right]$.

(3) If $\widehat{\beta}_{N} \leq \beta \leq 1$ so that agents are mildly present biased, every agent is unconstrained and EBC have no impact on their welfare.

The proposition mainly shows that given $\beta$, EBC would hurt (or have no impact on) more sophisticated agents and help the less sophisticated ones. Since the sophistication level reflects how much agents are aware of self-control problems they may face in the future, this awareness help agents be strategic in choosing today's behavior. Hence, given $\beta$, the welfare of the agent monotonically increases in $\alpha$. As aforediscussed, imposing borrowing limits have two opposing effects on agents. Since the more sophisticated agents are less inclined to borrow too much, they are more likely to be hurt by EBC. Vice versa for less sophisticated agents. Since given $\beta$, welfare gain under EBC $\Delta V_{y}$ monotonically decreases in $\alpha$, the sophistication effect of EBC is always negative. 


\section{Optimal government Policies}

We have shown two things. First, in the CM economy, naive or partially sophisticated agents cannot achieve either the first or the second best allocations, and b) in the EBC world, only when all agents are in a certain range for $\beta$ can they achieve at most the second best. Without further intervention, the first best solutions, $\left(a_{y}^{*}, a_{m}^{*}\right)$, are entirely unachievable by the market, with or without the CFPB. Then a natural question arises, can a (time consistent) public policy restore $\left(a_{y}^{*}, a_{m}^{*}\right) ?^{20}$ The answer is yes, but for that, the public policy has to work in tandem with the EBC (or the CPFB).

To see this, consider a government implementing a lump-sum, tax-transfer scheme where $\left(\tau_{y}, \tau_{m}, \tau_{o}\right)$, respectively, denotes the lump-sum (tax) transfer to the young, the middle aged and the old. In this case, the budget constraints for the agents become

$$
\begin{aligned}
& c_{y}+a_{y}=\omega_{y}+\tau_{y}, \\
& c_{m}+a_{m}=\omega_{m}+a_{y} R+\tau_{m}, \\
& c_{o}=\omega_{o}+a_{m} R+\tau_{o} .
\end{aligned}
$$

As will be shown below, such a policy can deliver the first best only when the credit market is operated under EBC.

Recall, the first best solutions $\left(a_{y}^{*}, a_{m}^{*}\right)$ satisfy

$$
c_{y}^{*}+\frac{c_{m}^{*}}{R}+\frac{c_{o}^{*}}{R^{2}}=\omega_{y}+\frac{\omega_{m}}{R}+\frac{\omega_{o}}{R^{2}} .
$$

As such, any such intergenerational policy must leave the present value of lifetime income, $Y \equiv$ $\omega_{y}+\omega_{m} / R+\omega_{o} / R^{2}$, unchanged, meaning

$$
\tau_{y}+\frac{\tau_{m}}{R}+\frac{\tau_{o}}{R^{2}}=0
$$

must hold.

First, consider how such a fiscal policy affects activities in the CM world. Given assumption (16), i.e., the young borrow and the middle aged save, an optimal fiscal policy requires the government to tax the middle aged and transfer the revenue to the young and old. The policy is consistent with what Boldrin and Montes (2005) and Wang (2014) propose. They show, when time consistent agents borrow to invest in education when young and the credit markets are imperfect (missing), the only way to replicate the complete market solutions is by "establishing publicly balanced education and pay-as-you-go pensions simultaneously, and by linking the two flows of payment via the market interest rate". In their setups, the joint institutional arrangements offer a perfect replacement for the missing credit market, and therefore, can replicate the complete market allocations.

\footnotetext{
${ }^{20}$ See also Guo and Caliendo (2014) for a setting where the government's policy itself is time inconsistent.
} 
However, when agents are time inconsistent, and are in the CM world, the above policy (satisfying (36) and leaving $Y$ unchanged) cannot affect allocations: in particular, the optimal youthful asset demand of naive and partially sophisticated agents, $a_{y}^{S, *}$, would remain unchanged. The same argument also applies to middle aged agents. Intuitively, with complete markets, any policy-induced rearrangement of after-tax endowments with no change in $Y$ can be entirely undone by appropriate borrowing and saving alterations by the agent. In particular, nothing prevents the middle-aged from undoing the plans laid out by the young (Andersen and Bhattacharya, 2019). The policy under complete markets is impotent.

Finally, we explore whether the policy can replicate the first-best solutions in an EBC economy. For any $\alpha \in[0,1]$, consider the following policy scheme

$$
\tau_{y}=-a_{y}^{*}, \tau_{m}=a_{y}^{*} R-a_{m}^{*}, \text { and } \tau_{o}=a_{m}^{*} R
$$

which satisfies (36). Notice, under this specific policy scheme, the following equation always holds,

$$
\frac{u^{\prime}\left(\omega_{m}+\tau_{m}\right)}{u^{\prime}\left(\omega_{o}+\tau_{o}\right)}=\delta R,
$$

which is equivalent to (10). Moreover, since agents are time inconsistent, $\beta<1$, we always have

$$
\frac{u^{\prime}\left(\omega_{m}+\tau_{m}\right)}{u^{\prime}\left(\omega_{o}+\tau_{o}\right)}>\beta \delta R
$$

which implies that given the policy scheme (37), a middle-aged agent has no incentive to save even if she incurred no debt in her youth. If that is the case, then, for sure, an indebted middleaged agent would choose to default on her youthful loan. Anticipating this, creditors will simply not lend to the young, implying $\bar{a}_{y}=0$. Evidently, under this specific arrangement of intergenerational transfers, both the young and the middle-aged are completely borrowing constrained, leaving the agent in autarky. As the consequence, the consumption of the agents reads

$$
\begin{aligned}
c_{y} & =\omega_{y}+\tau_{y}=\omega_{y}-a_{y}^{*} \\
c_{m} & =\omega_{m}+\tau_{m}=\omega_{m}+a_{y}^{*} R-a_{m}^{*} \\
c_{o} & =\omega_{o}+\tau_{o}=\omega_{o}+a_{m}^{*} R,
\end{aligned}
$$

which exactly replicates the first best solutions, $\left(c_{y}^{*}, c_{m}^{*}, c_{o}^{*}\right) !$ The policy scheme (37), in effect, resets the endowment in each period to equal the first best consumption levels. If the agents cannot borrow or save in their entire life, consuming their endowment is optimal. The policy scheme (37) with help from the CFPB ensures, in particular, that middle-aged agents cannot borrow. The CFPB offers a publicly provided commitment mechanism that effectively forces the agents to stay put on the first best path. ${ }^{21}$

\footnotetext{
${ }^{21}$ Recall when $\sigma>1$, we have $a_{y}^{*}<\left.a_{y}^{S, *}\right|_{\alpha \in(0,1]}$. In this case, given the policy scheme (37), sophisticated agents,
} 


\section{Concluding remarks}

This paper studies the role of markets and institutions in helping time-inconsistent agents deal with their self control problems. Using a textbook, exogenous endowment lifecycle model, it compares outcomes in a complete, unfettered credit market with those in an environment with borrowing constraints. These borrowing constraints are endogenously set in such a way that no borrower can borrow more than what she has incentive to pay back. The borrowing limit ensures that a borrower's expected discounted lifetime utility from participating in the asset market is at least as high as that of autarky, in which the borrower only consumes her exogenous endowment income every time period. These two market settings roughly correspond to a stylized world before and after the enforcement of the CFPB. The main take away from our paper is that, naive agents, those who are somewhat clueless about their impending loss of self control, may benefit from the borrowing restrictions that were put in place after the CFPB. In some cases, they would be better off compared to a world in which credit flowed freely without constraints. ${ }^{22}$

It is useful to record a few limitations of the current study with an eye to future research possibilities. First, we restrict attention to a setup where all agents are identical (have the same $(\alpha, \beta, \delta))$ and that these are known to all. Clearly, this is a vast simplification. Allowing for heterogeneity and unobservability in either $\alpha$ or $\beta$ or $\delta$ may allow for more interesting optimal contracts that induce self selection and separation. Similarly, the current analysis is silent on the issue of lenders designing contracts that exploit consumer naiveté and behavioral errors in general - see Heidhues and Köszegi (2010). ${ }^{23}$

While the present paper is focused entirely on the role of endogenous borrowing constraints and their impact on the lives of hyperbolic discounters, it is nevertheless interesting to ask if regulation went at it from a different angle, mandating saving for such consumers instead of restricting their access to credit. Andersen and Bhattacharya (2019) and Pardo (2019) offer a fresh discussion of this issue in the context of retirement saving. Findley and Hunt (2019) study

that are aware their future self may deviate would like to optimally choose $c_{y}^{S, *}=\omega_{y}-a_{y}^{S, *}$ by saving during youth. Notice the decision of $c_{y}^{S, *}$ is made upon on the expectation of $\beta^{E} \delta$. Since EBC cannot prevent the young from saving, does that mean the policy fails to replicate the first best solutions? The answer is, no. Since all information of the credit market is public, the sophisticated agents in an EBC economy also know they will not be allowed to borrow during the middle age. Knowing that to be the case, the sophisticated agents with $\sigma>1$ and $\alpha \in(0,1]$ understand that if they consume $c_{y}^{*}$ during the young age, the future selves will certainly follow the consumption plan $\left(c_{m}^{*}, c_{o}^{*}\right)$ even if they want to change the plan. Since $\left(c_{y}^{*}, c_{m}^{*}, c_{o}^{*}\right)$ is the first best consumption plan from the view at youth, those young sophisticated agents have no incentive to base their decision on $\beta^{E} \delta$.

${ }^{22}$ These ideas are reminiscent of a parallel discussion on bankruptcy reform, started in White (2007) and continuing, for example, in Nakajima (2017). This discussion makes the very useful distinction between a person whose principal identity is that of a borrower versus another whose main identity is a saver. As White (2007) neatly argues, "[...] hyperbolic discounters have dynamically inconsistent preferences; they prefer to borrow today and start saving tomorrow - but tomorrow never comes. These sophisticated hyperbolic discounters prefer a very pro-debtor bankruptcy system, since lenders ration credit more tightly and may not be willing to lend at all when the bankruptcy system is very pro-debtor. Thus, whether hyperbolic discounters prefer a pro-debtor or pro-creditor bankruptcy system depends on whether or not they recognize their tendency to borrow too much and favor a bankruptcy system that helps them control their own behavior."

${ }^{23}$ Senator Elizabeth Warren wrote in Oren and Warren (2008): "Consumers, their families, their neighbors, and their communities are paying a high price for systematic cognitive errors. Creditors have aligned their products to exploit such errors, driving up costs for many consumers." 
the Save More Tomorrow (SMarT) program to help hyperbolic discounters be better prepared for retirement. They find that any increased saving from participation in a SMarT program can be completely offset by crowding out of other saving vehicles or even more borrowing. In such a context, it may be worthwhile to study the joint regulation of borrowing and saving.

Finally, as the introduction argues, there is a sense in which the market in the EBC world generates commitment publicly. This means individuals, grappling with their self-control problems, do not need to invest (or, more generally, invest as much) in private commitment assets, such as annuities, on their own. But what if both private assets and publicly-generated commitment were jointly present? Would the latter, in the spirit of Krueger and Perri (2011) crowd out the former, and is that desirable? More bluntly, is the CFPB, in effect, killing off the private commitment asset market? These, and many other questions, are deserving of future inquiry. 


\section{References}

[1] Abrahám, A. and Cárceles-Poveda, E., 2010. Endogenous trading constraints with incomplete asset markets. Journal of Economic Theory, 145(3), pp.974-1004.

[2] Andersen, T.M., Bhattacharya, J. (2019) Why mandate young borrowers to contribute to their retirement accounts?. forthcoming, Economic Theory https://doi.org/10.1007/s00199-019-01235-2

[3] Andolfatto, D. and M. Gervais, (2006). Human Capital Investment and Debt Constraints, Review of Economic Dynamics, 9(1), pp 52-67.

[4] Azariadis, C., \& Lambertini, L. (2003). Endogenous debt constraints in lifecycle economies. Review of Economic Studies, 70(3), 461-487.

[5] Bechlioulis, A. P., \& Brissimis, S. N. (2019). Consumer debt non-payment and the borrowing constraint: Implications for consumer behavior. Journal of Banking and Finance, 101, 161172.

[6] Beshears, J., Choi, J. J., Laibson, D., \& Madrian, B. C. (2018). Behavioral household finance. In Handbook of Behavioral Economics: Applications and Foundations 1 (Vol. 1, pp. 177276). North-Holland.

[7] Bishnu, M. (2013). Linking consumption externalities with optimal accumulation of human and physical capital and intergenerational transfers. Journal of Economic Theory, 148(2), 720-742.

[8] Bishnu, M., Garg. T, Garg, S., Ray, T. (2020) Optimal Intergenerational Transfers: Public Education and Pensions; mimeo, ISI New Delhi

[9] Boldrin, M., Montes, A. 2005. The Intergenerational State: Public Education and Pensions, Review of Economic Studies, 72, 651-664.

[10] Broer, T., Kapička, M., \& Klein, P. (2017). Consumption risk sharing with private information and limited enforcement. Review of Economic Dynamics, 23, 170-190.

[11] Coeurdacier, N., S. Guibaud, and K. Jin (2015). Credit constraints and growth in a global economy. American Economic Review 105 (9), 2838-81

[12] Del Rey, E., \& Lopez-Garcia, M. A. (2019). On government-created credit markets for education and endogenous growth. forthcoming, Economic Modelling.

[13] Findley, T. Scott and Cottle Hunt, Erin, The Save More Tomorrow Program and the Household Balance Sheet: A Theoretical Investigation (September 6, 2019). Available at SSRN: https://ssrn.com/abstract=3315808 or http://dx.doi.org/10.2139/ssrn.3315808 
[14] Gathergood, J. (2012). Self-control, financial literacy and consumer over-indebtedness. Journal of Economic Psychology, 33(3), 590-602.

[15] Guo, N.L. and F.N. Caliendo (2014). Time-inconsistent preferences and time-inconsistent policies, Journal of Mathematical Economics, 51, 102-8

[16] Heidhues, P., \& Kőszegi, B. (2010). Exploiting naivete about self-control in the credit market. American Economic Review, 100(5), 2279-2303.

[17] Kehoe, T. J., \& Levine, D. K. (1993). Debt-constrained asset markets. Review of Economic Studies, 60(4), 865-888.

[18] Laibson, D, (1997), Golden eggs and hyperbolic discounting, Quarterly Journal of Economics, 112,443-77.

[19] Laibson, D., (2015), Why Don't Present-Biased Agents Make Commitments? American Economic Review, Papers \& Proceedings, 105(5), 267-272.

[20] Liu, L., Niu, Y., Wang, Y. (2019) Optimal consumption with time-inconsistent preferences. Economic Theory https://doi.org/10.1007/s00199-019-01228-1

[21] Nakajima, M. (2017). Assessing bankruptcy reform in a model with temptation and equilibrium default. Journal of Public Economics, 145, 42-64.

[22] Oren, Bar-Gill, and Warren Elizabeth. (2008) "Making Credit Safer." University of Pennsylvania Law Review 157(1), 1-100.

[23] Pardo, Oliver. (2019) On the Efficiency of Mandatory Retirement Savings Under Endogenous Borrowing Constraints, http://dx.doi.org/10.2139/ssrn.3400354

[24] Koszegi, B. (2014). Behavioral contract theory. Journal of Economic Literature, 52(4), 10751118.

[25] Krueger, D., \& Perri, F. (2011). Public versus private risk sharing. Journal of Economic Theory, 146(3), 920-956.

[26] Ryan, A., Trumbull, G., \& Tufano, P. (2011). A brief postwar history of US consumer finance. Business History Review, 85(3), 461-498.

[27] Tanaka, Tomomi, and Takeshi Murooka. (2012) Self-Control Problems and ConsumptionSaving Decisions: Theory and Empirical Evidence. Japanese Economic Review 63(1): 23-37.

[28] Wang, M. (2014). Optimal education policies under endogenous borrowing constraints. Economic Theory, 55(1), 135-159.

[29] White, M. J. (2007). Bankruptcy reform and credit cards. Journal of Economic Perspectives, 21(4), 175-200. 
[30] Xiao, Jing Jian, and Nilton Porto. (2019) Present bias and financial behavior. Financial Planning Review 2, no.2: 1048.

[31] Zhang, H. H. (1997). Endogenous borrowing constraints with incomplete markets. Journal of Finance, 52(5), 2187-2209. 


\section{Appendix}

Proof of Lemma 1: The proof relies on the expression of $\Phi^{\prime}\left(\beta^{E}\right)$ and $\Phi\left(\beta^{E}\right)+\beta \Phi^{\prime}\left(\beta^{E}\right)$. The expression of $\Phi^{\prime}\left(\beta^{E}\right)$, i.e., equation (20), can be easily derived from $\Phi^{\prime}\left(\beta^{E}\right)$. As for $\Phi\left(\beta^{E}\right)+$ $\beta \Phi^{\prime}\left(\beta^{E}\right)$, we have

$$
\begin{aligned}
\Phi\left(\beta^{E}\right)+\beta \Phi^{\prime}\left(\beta^{E}\right) & =\frac{\left[1+\delta\left(\beta^{E} \delta R\right)^{\frac{1-\sigma}{\sigma}}\right]\left[R+\left(\beta^{E} \delta R\right)^{\frac{1}{\sigma}}\right]+\left(\frac{1-\sigma}{\sigma}\right) \beta\left(1 / \beta^{E}-1\right)\left(\beta^{E} \delta R\right)^{\frac{1}{\sigma}} / \beta^{E}}{\left[R+\left(\beta^{E} \delta R\right)^{\frac{1}{\sigma}}\right]^{2-\sigma}} \\
& =\frac{\Psi+R+\delta\left(\beta^{E} \delta R\right)^{\frac{2-\sigma}{\sigma}}+\frac{\beta}{\sigma}\left(1 / \beta^{E}-1\right)\left(\beta^{E} \delta R\right)^{\frac{1}{\sigma}} / \beta^{E}}{\left[R+\left(\beta^{E} \delta R\right)^{\frac{1}{\sigma}}\right]^{2-\sigma}}>0,
\end{aligned}
$$

where $1 / \beta^{E}-1>0$ and by using $\beta^{E} \geq \beta$,

$$
\Psi=\frac{\left[\beta^{E}+\beta \beta^{E}+\left(\beta^{E}\right)^{2}-\beta\right]\left(\beta^{E} \delta R\right)^{\frac{1}{\sigma}}}{\left(\beta^{E}\right)^{2}}>0 .
$$

If $\Phi^{\prime}\left(\beta^{E}\right) \geq 0$, equation (22) obviously holds. If $\Phi^{\prime}\left(\beta^{E}\right) \leq 0$, we have

$$
\Phi\left(\beta^{E}\right)+\alpha \beta \Phi^{\prime}\left(\beta^{E}\right) \geq \Phi\left(\beta^{E}\right)+\beta \Phi^{\prime}\left(\beta^{E}\right)>0,
$$

which completes the proof for equation (22).

Proof of Proposition 3. We prove part 2 by examining the welfare impacts of EBC under different regimes of $\beta$.

(1) Welfare impacts on economies with intermediate levels of time inconsistency $\beta \in\left[\beta_{L}, \beta_{H}\right]$

Recall, in the EBC world, the agent with intermediate level of time inconsistency $\beta \in\left[\beta_{L}, \beta_{H}\right]$ is only borrowing constrained (unconstrained) in youth (middle age), and therefore has the actual lifetime welfare $V_{y}\left(\bar{a}_{y}, \beta\right)$. Evidently, EBC could improve their welfare if and only if $V_{y}\left(\bar{a}_{y}, \beta\right) \geq$ $V_{y}\left(a_{y}^{S, *}, \beta\right)$. Since EBC is incapable of improving the welfare of the fully sophisticated agent, which is the highest lifetime welfare an agent can actually achieve in the complete market, we in the proof let $a_{y}^{S, *}$ stand for $\left.a_{y}^{S, *}\right|_{\alpha \in[0,1)}$. 


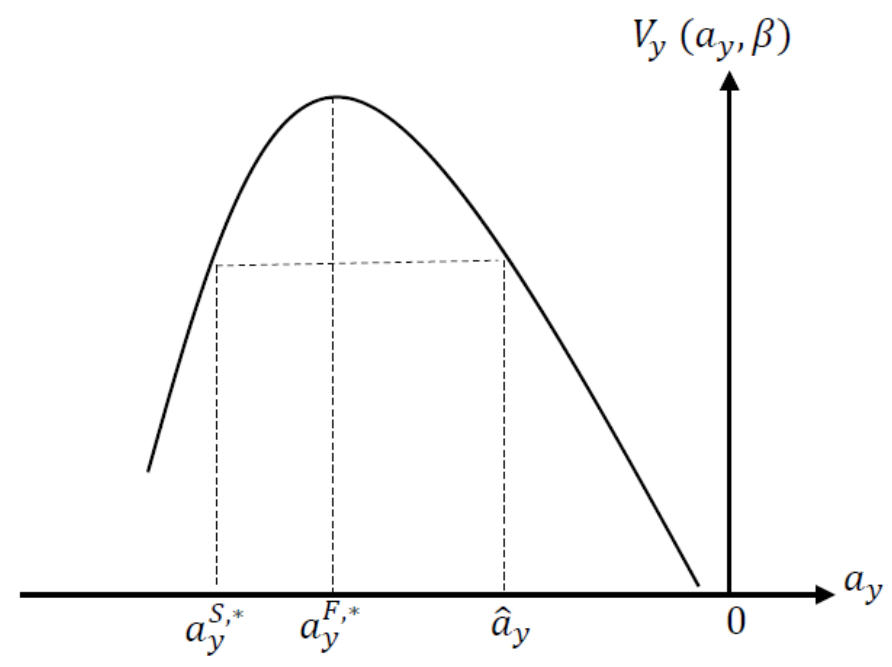

Figure 5: The welfare of agents

So, when does $V_{y}\left(\bar{a}_{y}, \beta\right) \geq V_{y}\left(a_{y}^{S, *}, \beta\right)$ obtain? As discussed, when the credit market is perfect, the second best solution $a_{y}^{F, *}$ solved by $\partial V_{y}\left(a_{y}^{F, *}, \beta\right) / \partial a_{y, t}=0$ yields higher welfare than $a_{y}^{S, *}$. Moreover, as shown in (26), when $\sigma>1$, the optimal youthful asset holding of the sophisticated agent is monotonically increasing in $\alpha$. Hence when $\sigma>1, a_{y}^{F, *}>a_{y}^{S, *}$ holds: the partially sophisticated borrow too much. Since $V_{y}\left(a_{y}, \beta\right)$ is concave in $a_{y}$ and peaked at $a_{y}^{F, *}$, as shown in the Figure $5, a_{y}^{S, *}$ is located to the left of $a_{y}^{F, *}$. Then there must exist a threshold value of youthful asset, $\widehat{a}_{y}$, under which $V_{y}\left(\widehat{a}_{y}, \beta\right)=V\left(a_{y}^{S, *}, \beta\right)$ and $\widehat{a}_{y}$ is located to the right of $a_{y}^{F, *}$, i.e., $\widehat{a}_{y}>a_{y}^{F, *}$. That is $\widehat{a}_{y}\left(\widehat{a}_{y} \neq a_{y, t}^{S, *}\right)$ is defined by

$$
\begin{aligned}
& \frac{\left(\omega_{y}-\widehat{a}_{y}\right)^{1-\sigma}}{1-\sigma}+\beta \delta \Phi(\beta) \frac{\left[\left(\omega_{m}+\widehat{a}_{y} R\right) R+\omega_{o}\right]^{1-\sigma}}{1-\sigma} \\
= & \frac{\left(\omega_{y}-a_{y}^{S, *}\right)^{1-\sigma}}{1-\sigma}+\beta \delta \Phi(\beta) \frac{\left[\left(\omega_{m}+a_{y}^{S, *} R\right) R+\omega_{o}\right]^{1-\sigma}}{1-\sigma} .
\end{aligned}
$$

For the naive or partially sophisticated agent with $\alpha \in[0,1)$, her complete market solution is $a_{y}^{S, *}$, but evidently, as shown in the Figure 5, any choice of $a_{y} \in\left[a_{y}^{S, *}, \widehat{a}_{y}\right]$ would be welfare improving for her. Hence in an EBC economy, if the borrowing limit for the young, $\bar{a}_{y}$, happens to be located in $\left[a_{y}^{S, *}, \widehat{a}_{y}\right], \mathrm{EBC}$ will increase the welfare of the naive or partially sophisticated agents endowed with $\beta \in\left[\beta_{L}, \beta_{H}\right]$.

We proceed to derive the conditions on $\beta$ that guarantee $\bar{a}_{y} \in\left[a_{y}^{S, *}, \widehat{a}_{y}\right]$. Firstly notice that when $\beta \rightarrow 0$ or $\beta=1$ so that the time inconsistency problem disappears, we have $a_{y}^{F, *}=a_{y}^{S, *}$ which in turn leads to $\widehat{a}_{y}=a_{y}^{F, *}$ at the two moments. Since $a_{y}^{F, *}$ monotonically increases in $\beta$ and $\widehat{a}_{y}$ is always larger than $a_{y}^{F, *}, \widehat{a}_{y}$ also increases in $\beta$ during $[0,1]$. Hence from the same starting point $-\omega_{y}-\omega_{m} / R-\omega_{o} / R^{2}$, the optimal youthful asset demand evaluated at $\beta=0$, the three curves of $\widehat{a}_{y}, a_{y}^{F, *}$ and $a_{y}^{S, *}$ all increase in $\beta$, with $\widehat{a}_{y}\left(a_{y}^{S, *}\right)$ always laid above (below) 
$a_{y}^{F, *}$, and converge on exactly the same endpoint at $\beta=1$. In contrast, starting from zero, the borrowing limit for the young $\bar{a}_{y}$ monotonically deceases in $\beta$, and as afore-discussed, becomes smaller than $a_{y}^{S, *}$ after $\beta_{H}$. Then as shown in Figure 6, there must exist an intersection between the two curves, $-\bar{a}_{y}(\beta)$ and $-\widehat{a}_{y}(\beta)$, where $\beta \in[0,1]$. Denote $\widehat{\beta}$ the point where $-\bar{a}_{y}(\beta)$ and $-\widehat{a}_{y}(\beta)$ get intersected. $\widehat{\beta}$ is solved by $\bar{a}_{y}(\widehat{\beta})=\widehat{a}_{y}(\widehat{\beta})$. Since by definition $-\widehat{a}_{y}$ is always smaller than $-a_{y}^{S, *}, \widehat{\beta}$ is smaller than $\beta_{H}$ but larger than $\beta_{L}$. Evidently when $\beta \in\left[\widehat{\beta}, \beta_{H}\right]$, we have $\bar{a}_{y} \in$ $\left[a_{y}^{S, *}, \widehat{a}_{y}\right]$. That is for all $\beta \in\left[\widehat{\beta}, \beta_{H}\right]$, EBC help correct the over-borrowing behavior of the naive and partially sophisticated young agents and therefore improves their welfare. Moreover, it is evident from Figure 6 that, if $\beta$ happens to be equal to $\widehat{\beta}_{F}$, the intersection point between the two curves $-\bar{a}_{y}(\beta)$ and $-a_{y}^{F, *}(\beta)$, EBC can help all naive and partially sophisticated agent achieve the second best solutions, $\left(a_{y}^{F, *}, a_{m}^{F, *}\right)$.

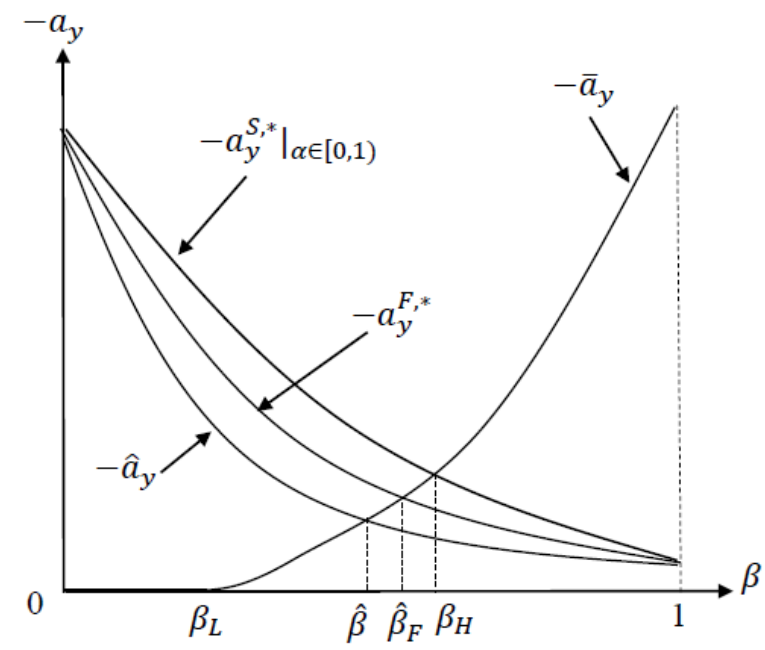

Figure 6: Youthful asset demands

(2) Welfare impact on economies with highly time inconsistent agents $\beta \in\left(0, \beta_{L}\right]$

In the EBC world, when $\beta \in\left(0, \beta_{L}\right]$, agents are borrowing constrained in both youth and middle age, and is in autarky in all of her life, with lifetime welfare equal to $u\left(\omega_{y}\right)+\beta \delta\left[u\left(\omega_{m}\right)+\delta u\left(\omega_{o}\right)\right]$. Consider a hypothetical case that when $\beta \in\left(0, \beta_{L}\right]$ so that agents are completely borrowing constrained when young, $\bar{a}_{y}=0$, but are unconstrained and therefore capable of smoothing consumption during middle and old age, i.e., borrowing during middle age and repay the loan during old age, which is impossible under the framework of EBC. For any $\beta \in\left(0, \beta_{L}\right]$, the welfare of agents in this hypothetical case is evidently higher than the actual welfare of the agents under EBC. Moreover, since agents are free to participate in the credit market during middle age, the welfare of agents in this hypothetical case is exactly equal to $V_{y}(0, \beta)$, the CM welfare of agents choosing zero asset at youth. We hence have $u\left(\omega_{y}\right)+\beta \delta\left[u\left(\omega_{m}\right)+\delta u\left(\omega_{o}\right)\right]<V_{y}(0, \beta)$.

In the CM world, the agent is free to borrow and save in all of her life and would optimally choose $a_{y}^{S, *}$ at youth. Recall that $\widehat{a}_{y}$ is determined by $V_{y}\left(a_{y}^{S, *}, \beta\right)=V_{y}\left(\widehat{a}_{y}, \beta\right)$. Since as shown in Figure $6 \widehat{a}_{y}$ is always smaller than $\bar{a}_{y}=0$ during $\left(0, \beta_{L}\right]$, we have $V_{y}\left(a_{y}^{S, *}, \beta\right)=$ 
$V_{y}\left(\widehat{a}_{y}, \beta\right)>V_{y}(0, \beta)$, which can be obtained from Figure 5 and lead to $V_{y}\left(a_{y}^{S, *}, \beta\right)>u\left(\omega_{y}\right)+$ $\beta \delta\left[u\left(\omega_{m}\right)+\delta u\left(\omega_{o}\right)\right]$. That is when $\beta \in\left(0, \beta_{L}\right]$, the CM solutions are Pareto dominant over the EBC solutions, meaning EBC cannot increase the welfare of agents. The results hold for all $\alpha \in[0,1]$.

Proof of Lemma 3. First we apply implicit function theorem to (38),

$$
\frac{\partial \widehat{a}_{y}}{\partial \alpha}=\frac{\left(\partial a_{y}^{S, *} / \partial \alpha\right) d V_{y}\left(a_{y}^{S, *}, \beta\right) / d a_{y}}{d V_{y}\left(\widehat{a}_{y}, \beta\right) / d a_{y}} .
$$

As shown in Figure 5, $d V_{y}\left(a_{y}^{S, *}, \beta\right) / d a_{y}>0$ and $d V_{y}\left(\widehat{a}_{y}, \beta\right) / d a_{y}<0$. Following directly from (26), $\partial a_{y}^{S, *} / \partial \alpha>0$ when $\sigma>1$. We hence have $\partial \widehat{a}_{y} / \partial \alpha<0$ when $\sigma>1$. That is as the agents become more sophisticated ( $\alpha$ gets larger), the curve of $-\widehat{a}_{y}$ in Figure 6 would move up. On the other hand, the curves of $a_{y}^{F, *}$ and $\bar{a}_{y}$ are independent of $\alpha$, which implies that the intersection point between $-\widehat{a}_{y}$ and $-\bar{a}_{y}, \widehat{\beta}$, will become larger. Similarly since $\partial a_{y}^{S, *} / \partial \alpha>0$ when $\sigma>1$, the curve of $-a_{y}^{S, *}$ in Figure 6 would move down as $\alpha$ increases, which in turn decreases the value of $\beta_{H}$.

Proof of Proposition 4. The proof relies on Figure 5 and Figure 6.

(1) $\beta<\widehat{\beta}_{F}$. As shown in the Proof of Proposition 3, when $\sigma>1$, the curve of $-a_{y}^{S, *}$ in Figure 6 monotonically moves down as $\alpha$ increases. Hence if $\sigma>1$ and $\beta<\widehat{\beta}_{F}$, following directly from Figure 6, we have $\bar{a}_{y}(\beta)>a_{y}^{S, *}(\beta)$ for all $\alpha^{\prime} s$, which means all naive and sophisticated agents are borrowing constrained. From (26), we recall that $\left.a_{y}^{S, *}(\beta)\right|_{\alpha \in[0,1)}$ is located to the left of $a_{y}^{F, *}$ in Figure 5 and monotonically increases to $a_{y}^{F, *}$ as $\alpha$ increases to one. Moreover since the borrowing limit $\bar{a}_{y}(\beta)$ is independent of $\alpha$, all borrowing constrained agents are forced to hold same amount of assets at youth, $\bar{a}_{y}(\beta)$, which is located to the right of $a_{y}^{F, *}$. Hence, there must exist a threshold value of $\widehat{\alpha}_{1} \in[0,1]$, defined by $V_{y}\left(\bar{a}_{y}, \beta\right)=\left.V_{y}\left(a_{y}^{S, *}, \beta\right)\right|_{\alpha=\widehat{\alpha}_{1}}$, such that $V_{y}\left(\bar{a}_{y}, \beta\right) \geq\left. V_{y}\left(a_{y}^{S, *}, \beta\right)\right|_{\alpha \in\left[0, \widehat{\alpha}_{1}\right]}$ and $V_{y}\left(\bar{a}_{y}, \beta\right) \leq\left. V_{y}\left(a_{y}^{S, *}, \beta\right)\right|_{\alpha \in\left[\widehat{\alpha}_{1}, 1\right]}$. The relationship between welfare gain of EBC and $\alpha$ follows directly from Figure 5 . Notice that $\widehat{\alpha}_{1}$ equals to zero if $V_{y}\left(\bar{a}_{y}, \beta\right) \leq\left. V_{y}\left(a_{y}^{S, *}, \beta\right)\right|_{\alpha=0}$.

(2) $\widehat{\beta}_{F}<\beta<\widehat{\beta}_{N}$. Using Figure 6, we can show that when $\widehat{\beta}_{F}<\beta<\widehat{\beta}_{N}$, there must exists a threshold value of $\widehat{\alpha}_{2}$, defined by $V_{y}\left(\bar{a}_{y}, \beta\right)=\left.V_{y}\left(a_{y}^{S, *}, \beta\right)\right|_{\alpha=\widehat{\alpha}_{2}}$, such that $\bar{a}_{y}(\beta) \geqslant\left. a_{y}^{S, *}(\beta)\right|_{\alpha \in\left[0, \widehat{\alpha}_{2}\right]}$ and $\bar{a}_{y}(\beta) \leq\left. a_{y}^{S, *}(\beta)\right|_{\alpha \in\left[\widehat{\alpha}_{2}, 1\right]}$. That is agents with sophistication level $\alpha \in\left[0, \widehat{\alpha}_{2}\right]$ are borrowing constrained and have to choose $\bar{a}_{y}(\beta)$, while agents with sophistication level $\alpha \in\left[\widehat{\alpha}_{2}, 1\right]$ are unconstrained and could optimally choose CM solutions. Moreover $\bar{a}_{y}(\beta)$ now is located to the left of $a_{y}^{F, *}$ in Figure 5, which can be directly used to prove the results of Part 2.

(3) $\widehat{\beta}_{N}<\beta<1$. Part 3 follows directly from that fact that $\widehat{\beta}_{N} \geq \beta_{H}$ for all $\alpha^{\prime} s$. 